\title{
Catalytic co-pyrolysis of grape seeds and waste tyres for the production of drop-in biofuels
}

\author{
O. Sanahuja-Parejo, A. Veses*, M.V. Navarro, J.M. López, R. Murillo, M.S. Callén, T. \\ García \\ Instituto de Carboquímica (ICB-CSIC), C/ Miguel Luesma Castán, 50018 Zaragoza, Spain. \\ *Corresponding author: a.veses@icb.csic.es
}

Keywords: co-pyrolysis, drop-in biofuels, biomass, waste tyres, calcined calcite

\section{Abstract}

Catalytic co-pyrolysis of grape seeds and waste tyres was performed in a fixed-bed reactor using calcined calcite as a catalyst. The organic phase obtained was analysed for its further application as a potential and stable drop-in fuel. Remarkable positive effects were achieved after the joint incorporation of both waste tyres and calcined calcite to grape seeds in the process. More specifically, the addition of considerable amounts of waste tyres (between 20 and $40 \mathrm{wt} \%$ ) with a constant ratio of feedstock to calcined calcite of 1 were considered the optimal experimental conditions to promote positive synergistic effects on bio-oil yields and its characteristics as a fuel. Thus, when the proportion of waste tyres in the feed reached $40 \mathrm{wt} \%$, the organic phase yield was considerable improved, reaching up values higher than $73 \mathrm{wt} \%$, significantly greater than those obtained from conventional pyrolysis (61 wt\%). Moreover, oxygen content was reduced to $4.2 \mathrm{wt} \%$, minimizing any problems related to corrosivity and instability. HHV was enlarged from 15.3 up to $27.3 \mathrm{MJ} / \mathrm{kg}$, significantly increasing the value of the resulting bio-oil. $\mathrm{pH}$ values and specially total acid number were also improved reaching values down to $1 \mathrm{mg} \mathrm{KOH} / \mathrm{g}_{\text {bio-oil }}$ in all cases. Additionally, a more valuable chemical composition was achieved since the production of aromatic and cyclic hydrocarbons was maximized, while a significant reduction in phenolic compounds was 
achieved. Moreover, bio-oil sulphur content was drastically reduced in comparison with the pyrolysis of waste tyres by itself from 0.6 down to $0.2 \mathrm{wt} \%$. The role of calcined calcite was directly related to the promotion of dehydration reactions of acids and phenols in order to generate hydrocarbons. On the other hand, radical interactions between the biomass and waste tyres pyrolysis products played a fundamental role in the production of more valuable compounds. Finally, the $\mathrm{CO}_{2}$ capture effect produced a more environmentally friendly gas while maintaining its calorific value.

\section{Introduction}

The appropriate use of renewable sources is considered crucial to meet the challenge of reducing the environmental impact caused by the extraction of fossil fuels and their processing in present-day refineries. Lignocellulosic biomass is one of the most promising alternatives for reducing fossil fuel dependence, because: (a) it is the only carbon-containing renewable source that can produce biofuels that are similar to fossil fuels; (b) it is considered inexpensive [1]; and (c) it does not compete with food production. Among all the possible techniques that can be used to enhance the value of lignocellulosic biomass [2], fast pyrolysis is an attractive alternative because it is the only thermochemical process that can produce a liquid biofuel in a simple one-step process. Additionally, solid and gas fractions are produced. These fractions can be used as energy sources to cover the thermal requirements of the process [3, 4]. In fact, the success of any biomass pyrolysis process lies in the exploitation of all by-products. In this regard, the application of an autothermal system, where gas and char fractions are used as an energy source for the process and for power generation, seems an appropriate solution $[5,6]$. 
Biomass pyrolysis can be defined as the thermal degradation of biomass in the absence of oxygen at moderate temperatures $\left(450-600{ }^{\circ} \mathrm{C}\right)$. The potential of this technology allows a liquid fraction (bio-oil) yield of $60-70 \mathrm{wt} \%$ to be achieved depending on the experimental conditions and reactor type [7]. After the process, the organic fraction of bio-oil, which can be easily separated, becomes the most valuable product, since it is considered a potential source of second-generation biofuels [8]. However, bio-oil quality needs to be improved in order to be used in current power generation infrastructures and/or further processed at state of the art bio-refineries [9-11]. Bio-oils consist of a complex mixture of hundreds of organic compounds, mainly reactive oxygenated compounds, which make them unstable and give them lower heating values in comparison to currently available commercial liquid fuels. Moreover, bio-oils are highly acidic in nature, mainly due to the presence of carboxylic acids, and can cause severe problems of corrosion. For these reasons, bio-oils face a great challenge in order to be considered as a real alternative to fossil fuels able to replace commercial liquid fuels, such as gasoline or diesel. Therefore, the most cost-effective solution lies on the development of drop-in fuels, where biomass pyrolysis liquids would be added to those obtained from fossil fuels in existing refineries [12-14]. Thus, the short-term objectives for the production of second-generation biofuels are focused on obtaining a more stable and deoxygenated bio-oil, which could be mixed with current conventional fuels [1517] as is already the case with first-generation biofuels.

The most promising alternatives for the production of drop-in biofuels from pyrolysis, owing to their lower cost and simplicity, are those performed in situ during the process. Two different approaches emerge as the best potential solutions. First, the incorporation of different low-cost and/or regenerable cracking catalysts, also known as catalytic pyrolysis [18-21] and, second, the co-feeding of different polymers/plastic residues such 
as polyethylene (PE), polypropylene (PP), polystyrene (PS) or waste tyres (WTs) [22$25]$ to the process. The state of the art of these technologies has been described in numerous reviews [6, 26-30] and there is consensus that catalytic co-pyrolysis, where both solutions are simultaneously implemented, is a much promising technology than the catalytic pyrolysis of biomass on its own. The level of success of this technology would lie in the occurrence of favourable synergistic effects caused by radical interactions during feedstock devolatilization, resulting in a bio-oil (the organic fraction) without phase separation. In this sense, it is worth of mention that those liquid organic fractions separately obtained from the pyrolysis of either polymer residues or lignocellulosic biomass are not miscible [4]. Thus, their direct processing cannot be performed in a bio-refinery. Moreover, the proportion of plastic-derived material in the feedstock should be considered a key factor in order to ensure the feasibility of any large-scale catalytic co-pyrolysis process.

All catalytic co-pyrolysis research conducted to date has shown very promising results in obtaining an improved liquid fraction, not only in terms of higher liquid yields but also better fuel properties $[26,30]$. The resulting bio-oil not only presents a lower oxygen content, and consequently a higher heating value, than those obtained by conventional pyrolysis, but also lower acidity and water content. Moreover, a pronounced increase in aromatic hydrocarbon composition can be obtained. Additionally, lower coke formation on the catalyst surface is observed, mainly due to the promotion of hydrogen transfer reactions enhanced by the higher hydrogen content of the plastic-type residues [26]. More specifically, Dorado et al.[25] tested several types of biomass and plastic-derived residues for the production of drop-in fuels, and concluded that certain combinations of plastic/biomass blends favour the production of particular aromatic products (toluene, xylene and ethylbenzene) in the presence of $\mathrm{H}$ - 
ZSM5. Similar tendencies were observed by other authors [31, 32] where the catalytic co-pyrolysis of pine wood and LDPE with zeolitic catalysts enhanced the production of toluene and xylenes. Similarly, studies focusing on the catalytic co-pyrolysis of biomass model components (cellulose, hemicellulose or lignin) with waste tyres using SBA-15, MCM-41 and HZSM-5 [22] catalysts were conducted in a lab-scale reactor, showing an increase in the aromatic fraction yield. In line with this, Rezaei et al [33] studied hierarchical mesoporous $\mathrm{Y}$ and Al-SBA-15 for the catalytic co-pyrolysis of yellow poplar and PE. The authors revealed a high selectivity to aromatic hydrocarbons production attributed to the effective pore structure, large channels, and high acidity of the catalysts as well as the high $\mathrm{H}_{2}$ evolved from PE pyrolysis. However, it should be pointed out that, as in the case of biomass catalytic pyrolysis, catalysts deactivation as a result of coke deposition on the zeolite-based catalysts [26] and the formation of polycyclic aromatic hydrocarbons are still important challenges which need to be resolved. In addition, all these tests were conducted mainly through zeolitic materials entailing an extra-cost associated to the addition of new or regenerated catalyst. Hence, the application of low-cost catalysts such as $\mathrm{CaO}$, that has already shown promising results in the catalytic pyrolysis of biomass [5, 19] could emerge as a promising alternative, enhancing positive synergistic effects in the catalytic co-pyrolysis process.

Among all available lignocellulosic biomass, agricultural residues such as grape seeds (GSs) rise as a worldwide available biomass. For the moment, GSs have been barley studied at pyrolysis processes despite its high-energy content that makes it a potential renewable feedstock for energy production [34]. For instance, Xu et al. [34] demonstrated that the organic phase obtained after the pyrolysis process could be an attractive fuel with significant energy content. In addition, Brebu et al. [35] also studied the pyrolysis of GSs and the co-pyrolysis process of GSs and polyethylene, concluding 
that interactions between both materials were leading to positive effects on both liquid yields and bio-oil composition. As shown, the number of works using GSs as feedstock is limited and a wider range of studies using this raw material needs to be conducted.

On the other hand, regarding the plastic waste-to-energy conversion, WTs valorisation could play a crucial role since WTs wastes represent a great annual generation. Moreover, since WTs pyrolysis has been successfully conducted [36-38] and the positive effect on their addition to the pyrolysis of biomass has been also demonstrated $[23,39]$, the catalytic co-pyrolysis of GSs and WTs with $\mathrm{CaO}$ as catalyst could be an attractive, novel and low-cost solution for the production of drop-in fuels ensuring both the sustainability and feasibility of the process.

In this work, we present the findings of the study of the catalytic co-pyrolysis of GSs and WTs using $\mathrm{CaO}$ as a catalyst. This strategy is a new, simple and low-cost alternative for the obtention of high quality bio-oils to be used as drop-in biofuels. In order to accomplish this aim, a study was made of the effect of two different variables, the GSs-to-WTs ratio and feedstock (GSs+WTs)-to-catalyst ratio, on pyrolysis products, and the influence of these variables on the characteristics of the liquid product (bio-oil) was more extensively analysed. In addition, synergy effects between both feedstocks, in the presence and absence of catalyst, were assessed based on the rule of mixtures.

\section{Materials and methods}

\subsection{Biomass, waste tyres and catalyst}

The biomass used in the present study was GSs (Vitis vinifera), obtained from the northeast area of Spain. The fresh biomass was previously dried in order to reduce moisture levels to below $2 \mathrm{wt} \%$, and then used directly. Granulated WTs with a particle size of 
between 2 and $4 \mathrm{~mm}$ were supplied by a Spanish WTs recycling company (Gesneuma

S.L.U.). WTs were composed of rubber without the steel thread and the textile netting (moisture content of $0.9 \mathrm{wt} \%$ ).

Table 1 summarizes the main properties of both feedstocks. The lower heating value (LHV) was measured experimentally with an IKA C-2000 calorimetric bomb using the Spanish (UNE) standard procedure UNE 164001 EX. Proximate analysis of the received feedstock was determined according to UNE-EN ISO 18134-3 for moisture, UNE-EN ISO 18122 for ash proportion, and UNE-EN ISO 18123 for volatile matter. Fixed carbon was determined by difference. Ultimate analysis of the feedstock was determined in a Thermo flash 1112, according to UNE EN 5104, and oxygen content was determined by difference. At this point, it is worth mentioning that great differences were detected between both feedstocks. Table 1 shows that while GSs were characterized by a remarkably high oxygen content (33.7 wt\%), implying a relative low LHV (22.2 MJ/kg), the composition of the WTs was characterized by an important source of carbon with low oxygen content, implying heating values similar to or even higher than those obtained from fossil fuels (\% C: $87.9 \mathrm{wt} \%, \% \mathrm{H}: 3.3 \mathrm{wt} \%$ and LHV: $37 \mathrm{MJ} / \mathrm{kg}$, respectively).

Calcined calcite $(90 \% \mathrm{CaO}$, Calcinor) was used as the catalyst in this study. The $\mathrm{CaO}$ was commercially available and obtained after the calcination of limestone at $900{ }^{\circ} \mathrm{C}$. Particle size distribution was in the range of 300-600 $\mu \mathrm{m}$.

\subsection{Thermogravimetric analysis}

171 The aim of this thermogravimetric analysis was to study the thermal behaviour of both

172 feedstocks under pyrolysis conditions. Thus, the thermogravimetric analysis was 173 performed for each feedstock starting at room temperature until $700{ }^{\circ} \mathrm{C}$ was reached, using a heating rate of $100{ }^{\circ} \mathrm{C} / \mathrm{min} .100{ }^{\circ} \mathrm{C} / \mathrm{min}$ was selected as the most representative 
temperature to carry out this analysis because this value is in line with the heating rate achieved in the further pyrolysis experiments in the fixed bed reactor. The solid weight loss and the temperature were recorded in a Netzsch Libra F1 Thermobalance. The sample weight used in all experiments was approximately $9 \mathrm{mg}$, and $\mathrm{N}_{2}(50 \mathrm{Nml} / \mathrm{min})$ was used as the carrier gas.

\subsection{Fixed bed reactor}

Co-pyrolysis experiments were carried out in a stainless steel fixed-bed reactor $(52.5 \mathrm{~cm}$ length and $5 \mathrm{~cm}$ internal diameter), shown in Figure 1. This reactor was specifically designed to carry out the process studied, with the peculiarity of incorporating a vertical mobile liner, where the feedstock was deposited, and to ensure the higher heating rates needed for the devolatilization process. Samples of $50 \mathrm{~g}$ were pyrolysed using $\mathrm{N}_{2}$ as the carrier gas $(300 \mathrm{~mL} / \mathrm{min})$. The reactor was heated externally by means of electrical resistance at a rate of approximately $100{ }^{\circ} \mathrm{C} / \mathrm{min}$ until the final pyrolysis temperature $\left(550{ }^{\circ} \mathrm{C}\right)$ was reached. The reaction time considered for completion of the pyrolysis process was set to 30 minutes. A tailor-made condenser using a cold-water coil at $3{ }^{\circ} \mathrm{C}$ was used to collect the condensable gas fraction. The liquid and solid yields were obtained by weight, while the non-condensable gas yield was calculated by the gas composition sampled in a gas bag located after the filter (see Figure 1). Several runs considering only GSs, WTs and the GSs/WTs mixture (80/20 wt\%) were performed from three to five times, keeping a relative standard deviation lower than $5 \%$ in product yields. The remaining experiments were carried out twice ensuring a RSD $<5 \%$. Only those experiments with mass balance of $100 \pm 5 \%$ were determined to be valid. Different feedstock mixtures were studied, on a mass basis: $100 \%$ GSs (100/0); $95 \%$ GSs and $5 \%$ WTs (95/5); $90 \%$ GSs and $10 \%$ WTs (90/10); $80 \%$ GSs and $20 \%$ WTs 
200 (80/20); $60 \%$ GSs and $40 \%$ WTs (60/40); and $100 \%$ WTs (0/100). The same

201

202

203

204

205

206

207

208

209

210

211

212

213

214

215

216

217

218

219

220

221

222

223

224

proportions were analysed incorporating $\mathrm{CaO}$ to the feed while keeping a feedstock-to$\mathrm{CaO}$ ratio of 1 . Finally, the impact of the catalyst-to-feedstock ratio was also analysed, keeping a GSs-to-WTs ratio of 80/20 while varying feedstock-to-CaO ratios $(3: 1,2: 1$, $1: 1,1: 2$ by weight)

\subsection{Product characterization}

After the co-pyrolysis experiments, the different by-products (liquid, solid and gas fractions) were characterised. As it was expected, a heterogeneous liquid fraction comprising two different phases was obtained. The recovered sample was centrifuged at $1500 \mathrm{rpm}$ for 15 minutes and both liquid layers (aqueous/bottom layer and organic/top layer) were subsequently collected by decantation. Then, the organic liquid phase was analysed in triplicate by determining different physicochemical properties according to standard methods. Physicochemical characterization of the organic liquid fraction was carried out by ultimate composition (Carlo Erba EA1108), calorific value (IKA C2000), water content by Karl-Fischer titration (Crison Titromatic) according to ASTM E203-96, and total acid number (TAN) and pH (Mettler Toledo T50). The chemical composition of the organic phase was analysed by GC/MS using a Varian CP-3800 gas chromatograph connected to a Saturn 2200 Ion Trap Mass Spectrometer. A capillary column, CP-Sil $8 \mathrm{CB}$, low bleed: 5\% phenyl, 95\% dimethylpolysiloxane, $(60 \mathrm{~m}, 0.25$ mm i.d., film thickness $0.25 \mu \mathrm{m}$ ) was used. An initial oven temperature of $40{ }^{\circ} \mathrm{C}$ was maintained for 4 minutes. Then, a heating rate of $4{ }^{\circ} \mathrm{C} / \mathrm{min}$ was implemented to reach a final column temperature of $300{ }^{\circ} \mathrm{C}$. This temperature was maintained for 21 minutes. The carrier gas was He (BIP quality) at a constant column flow of $1 \mathrm{mLN} / \mathrm{min}$. The injector, detector and transfer line temperatures were $280{ }^{\circ} \mathrm{C}, 200{ }^{\circ} \mathrm{C}$ and $300{ }^{\circ} \mathrm{C}$, 
respectively. Sample volumes of $1 \mu \mathrm{L}\left(1: 25\right.$, wt $\%$, in a mixture of $\left.1: 1 \mathrm{CH}_{2} \mathrm{Cl}_{2}: \mathrm{C}_{2} \mathrm{H}_{6} \mathrm{O}\right)$

226

227 were injected applying a split ratio of $25: 1$, with a solvent delay of 7.5 minutes. The MS was operated in electron ionization mode within the $35-550 \mathrm{~m} / \mathrm{z}$ range. Each peak attributed to a determined compound was integrated according to the corresponding $\mathrm{m} / \mathrm{z}$ (reported in Table A.1-Table A.5, appendix A). Each sample was analysed twice, and the results were computed as an average. The percentage of each compound in the biooil was determined by area normalization, i.e. the quotient between the area of each peak and the total area, and the compounds were grouped by families. The interpretation of the mass spectra given by the GC/MS analyses was based on an automatic search of the NIST 2011 library.

The solid fraction (char) was characterized by measuring its calorific value (IKA C2000). The non-condensable gases were determined by gas chromatography using a Hewlett Packard series II coupled to a TCD detector. The chromatograph was equipped with a Molsieve $5 \AA$ column to analyse $\mathrm{H}_{2}, \mathrm{O}_{2}, \mathrm{~N}_{2}$ and $\mathrm{CO}$ and with a HayeSep Q column to analyse $\mathrm{CO}_{2}$ and light hydrocarbons. Both oven programmes used were isothermal at $60{ }^{\circ} \mathrm{C}$ and $90{ }^{\circ} \mathrm{C}$ for the Molsieve and Hayesep Q columns, respectively. Additionally, gas phase higher hydrocarbons were measured through a capillary column in a Varian GC using the following temperature programmed method: isothermal at 60 ${ }^{\circ} \mathrm{C}$ for 5 minutes and then, a heating rate of $20{ }^{\circ} \mathrm{C} / \mathrm{min}$ up to $120^{\circ} \mathrm{C}$, keeping that temperature for 5 minutes.

\subsection{Synergy evaluation}

The occurrence of synergistic interactions for both the product yields and the bio-oil properties were analysed based on a comparison between the experimental pyrolysis results and the theoretical pyrolysis data. Theoretical values were obtained based on the rule of mixtures, assuming that there were no interactions between the pyrolytic vapour 
molecules (see Equation 1). In the equation, $\alpha_{1}$ and $\alpha_{2}$ represent the product yield or physicochemical property from biomass and tyre, respectively; while $w_{1}$ and $w_{2}$ represent the mass proportion for each feedstock. If the experimental co-pyrolysis leads to a bio-oil property value better than the theoretical $y$ value, it can be concluded that a vapour interaction is likely taking place, and consequently, there is a positive synergistic effect.

$y=w_{1} * \alpha_{1}+w_{2} * \alpha_{2}$

It is worth highlighting that the properties of the mixture of pyrolytic liquids from each feedstock cannot be evaluated experimentally, since the GSs bio-oil and the WTs liquid fraction are not miscible. In order to understand the complex mechanism of catalytic copyrolysis, an attempt was made to separate the interactions occurring among radicals released during solids devolatilization from those of the catalytic upgrading process taking place at the $\mathrm{CaO}$ catalyst. In order to do so, theoretical values were calculated for both conventional co-pyrolysis (from conventional pyrolysis of GSs and WTs on their own) and catalytic co-pyrolysis (from catalytic pyrolysis of GSs with $\mathrm{CaO}$ and of WTs with $\mathrm{CaO}$ on their own).

\section{Results and discussion}

\subsection{Thermogravimetric analyses}

Thermogravimetric analysis is a very useful technique to study and understand the pyrolysis behaviour of different feedstocks under well-defined conditions. Thermogravimetric analyses were performed at a heating rate of $100{ }^{\circ} \mathrm{C} / \mathrm{min}$ in order to mimic the calculated conditions applied in the experimental fixed-bed reactor. The results obtained for weight loss and rate of weight loss for both samples of GSs and WTs are compiled in Figure 2. Being a form of lignocellulosic biomass, GSs form a 
complex solid mainly composed of hemicellulose and cellulose, which consist of monomeric sugars, and lignin, which is a complex, cross-linked, three-dimensional aromatic polymer made up of phenyl-propane units [40]. At this heating rate, the decomposition pathway starts with the degradation of the weakest parts of the lignin at around $200{ }^{\circ} \mathrm{C}$, followed by the decomposition of hemicellulose at between $250{ }^{\circ} \mathrm{C}$ and $350{ }^{\circ} \mathrm{C}$, and the devolatilization of the cellulose component at between $350{ }^{\circ} \mathrm{C}$ and 400 ${ }^{\circ} \mathrm{C}$. After this temperature, only decomposition of the strongest bonds in the lignin takes place up to $600{ }^{\circ} \mathrm{C}$. Finally, at higher temperatures, only the degradation of inert substances and fixed carbon continues with a very low reaction rate. The WTs sample comprising tyre rubber was a blend of additives [41], natural rubber (NR) and synthetic rubber: styrene-butadiene copolymer (SBR) and butadiene rubber (BR) as well as carbon black and fillers. In the literature [42-44], the process is described by an initial decomposition of additives, followed by NR decomposition, and finally, the synthetic polymers SBR and BR degrade at increasing temperatures. At the heating rate applied in this study, the decomposition of the additives was observed starting at $250{ }^{\circ} \mathrm{C}$; the weight loss observed at between $350{ }^{\circ} \mathrm{C}$ and $450{ }^{\circ} \mathrm{C}$ could describe the $\mathrm{NR}$ decomposition, with a highest rate of mass loss centred at $400{ }^{\circ} \mathrm{C}$; and SBR and $\mathrm{BR}$ degradation could be described at higher temperatures, at about $450{ }^{\circ} \mathrm{C}$ and $500{ }^{\circ} \mathrm{C}$, respectively.

As expected, devolatilization of the GSs started at a lower temperature than that of the WTs. However, as the thermograms indicate, there was a large overlap, with devolatilization of both feedstocks taking place within the same temperature range of between $200{ }^{\circ} \mathrm{C}$ and $550{ }^{\circ} \mathrm{C}$, approximately. This suggests that the radicals released during the pyrolysis process could coexist within this temperature range and that interactions are likely to take place between them. On the other hand, $550{ }^{\circ} \mathrm{C}$ seems to 
be the optimum temperature at which to carry out the co-pyrolysis process in order to ensure a complete conversion of both feedstocks.

\subsection{Influence of WTs and $\mathrm{CaO}$ in product distribution}

In order to analyse the effect of the addition of WTs on product yields and the characteristics of by-products, different experiments were carried out introducing 5,10 , 20 and $40 \mathrm{wt} \%$ of WTs together with GSs in the fixed bed reactor. As can be observed in Table 2 (section A), when GSs and WTs were pyrolysed on their own, it was possible to obtain $38.8 \mathrm{wt} \%$ and $43.7 \mathrm{wt} \%$ of liquid fraction, respectively. It can also be observed that bio-oil from GSs pyrolysis comprised two phases (aqueous and organic), while the WTs oil consisted of only one organic phase. Table 2 (section B) also shows that the cofeeding of WTs increased the liquid production from the pyrolysis of GSs alone, reaching values close to $40 \mathrm{wt} \%$ when all the different proportions were analysed. These values were fairly similar to the theoretical values calculated from the mass balance (see Table 2, section C). It is worthy of note that although no apparent synergistic effects could be observed, a liquid organic fraction with only one phase was produced. This fact evidenced the existence of radical interaction between those species released during the thermal degradation of both feedstocks, given that the pyrolytic liquids produced from each solid are not miscible. On the other hand, the solid fraction remained at expected yields, and the same conclusion could be made with regard to the gas fraction, in which only relatively insignificant differences could be observed.

Based on previously reported results, $\mathrm{CaO}$ was selected as the cracking catalyst for the catalytic co-pyrolysis experiments [5, 19]. Different experiments were carried out at increasing amounts of WTs $(5,10,20$ and $40 \mathrm{wt} \%)$, with a fixed GSs/WTs-to-CaO ratio of 1:1 maintained. Catalytic pyrolysis of each feedstock with $\mathrm{CaO}$ was also carried out 
324 for reference. Table 2 (section E) shows that the simultaneous incorporation of WTs and

$325 \mathrm{CaO}$ to the catalytic co-pyrolysis process again resulted in an increment in the liquid 326 yield, as theoretically expected. However, percentages higher than those theoretically

327 calculated for the co-pyrolysis of GSs and WTs alone were obtained after $\mathrm{CaO}$ addition

328 (up to $10 \%$, approximately), evidencing a positive synergistic effect. This effect was 329 more pronounced when high percentages of WTs were co-processed (20 and $40 \mathrm{wt} \%$ ).

330 As expected, the solid fraction yield increased, while the gas fraction yield experienced 331 a decrease, a consequence of $\mathrm{CaCO}_{3}$ formation owing to the $\mathrm{CO}_{2}$ capture associated 332 with these types of materials.

Finally, it should be noted that feedstock-to-CaO ratio also had a great influence on product distribution. Higher proportions of $\mathrm{CaO}$ led to increasing liquid yields, which were balanced with lower gas yield, with a liquid proportion high as $49.5 \mathrm{wt} \%$ achieved for the highest feedstock-to- $\mathrm{CaO}$ ratio. It can be assumed that the promotion of cracking reactions by $\mathrm{CaO}$ catalyst can lead to the formation of condensable organic compounds through retrogressive reactions, thus increasing the liquid fraction yield.

It is quite obvious that not only the liquid fraction yield is of importance after any copyrolysis process, but that a well-defined phase distribution also plays a fundamental role in determining the feasibility of the process. Table 2 provides a summary of phase distribution, determined in all cases by centrifugation-decantation method. Nevertheless, after either co-pyrolysis or catalytic co-pyrolysis experiments, a homogeneous organic phase was obtained in all cases after water phase separation.

347 Hence, it should be highlighted that the incorporation of WTs produced a higher organic fraction yield in the bio-oil, achieving values of up to 66.2 and $77.4 \mathrm{wt} \%$ when the proportion of WTs was 20 and $40 \mathrm{wt} \%$, respectively, which were similar values to those 

incorporation of $\mathrm{CaO}$ to the co-pyrolysis process since the organic fraction yield barely changed with increasing amounts of WTs, leading to yield values lower than those theoretically expected. These results are in line with the lower yield obtained after the catalytic pyrolysis of GSs with $\mathrm{CaO}$ (Table 2, Section D), as it was mainly observed that the incorporation of catalysts to the pyrolysis process generally entailed a decrease in the organic fraction, although with upgraded properties [45]. This effect can mainly be explained by the dehydration reactions enhanced by $\mathrm{CaO}[5,19,46]$, increasing the aqueous fraction in the final bio-oil (see Table 2, section E). In fact, when the maximum amount of $\mathrm{CaO}$ was introduced into the reactor feed (Table 2, Section G), the lowest organic yield was found $(42.0 \mathrm{wt} \%)$, confirming the key role of $\mathrm{CaO}$ in promoting dehydration reactions.

\subsection{Influence of WTs and $\mathrm{CaO}$ in gas composition}

Table 3 summarizes the non-condensable gas composition. Gas composition after GS pyrolysis was characterized as a rich $\mathrm{CO}$ and $\mathrm{CO}_{2}$ gas whilst $\mathrm{H}_{2}$ remained at relevant values (18 vol\%), reaching a heating value of up to $15.3 \mathrm{MJ} / \mathrm{Nm}^{3}$. However, WT pyrolysis gas was characterized as a hydrocarbon and $\mathrm{H}_{2}$ rich gas, with a high $\mathrm{HHV}$ (49.3 $\left.\mathrm{MJ} / \mathrm{Nm}^{3}\right)$. The incorporation of WTs to the feed implied a proportional reduction in $\mathrm{CO}$ and $\mathrm{CO}_{2}$ as the proportion of WTs increased. Additionally, a noteworthy increase in both $\mathrm{H}_{2}$ and hydrocarbons concentration was also achieved. As a consequence, the non-condensable gas raised its HHV as the proportion of WTs increased in the feed, reaching a value of $29.3 \mathrm{MJ} / \mathrm{Nm}^{3}$ when the proportion of WTs was $40 \mathrm{wt} \%$.

The effect of $\mathrm{CaO}$ addition resulted in meaningful differences in the non-condensable gas composition. These effects could be directly associated with the implicit $\mathrm{CO}_{2}$ 
capture and $\mathrm{H}_{2}$ production from the water gas shift reaction enhanced by $\mathrm{CaO}[47,48]$. Thus, after catalytic pyrolysis of GSs, $\mathrm{H}_{2}$ production rose from 18.1 to 49 vol\%, while $\mathrm{CO}_{2}$ decreased from 38.8 to 6.3 vol\%.

Focusing on the catalytic co-pyrolysis process, it can be highlighted that there was additional $\mathrm{H}_{2}$ production, in comparison with that produced in catalytic pyrolysis (15$20 \%$ ), which was also higher than expected theoretical values (see Table 3). This fact could be very positive since $\mathrm{H}_{2}$-transfer reactions could be a fundamental building block in the upgrading of bio-oils [49]. On the other hand, $\mathrm{CO}_{2}$ production decreased to values lower than 3.6 vol\%. Finally, HHV values were about $25-27 \mathrm{MJ} / \mathrm{Nm}^{3}$, indicating an increase of $40 \%$ over those of the pyrolysis of GSs alone, and slightly higher than those found in the catalytic pyrolysis of GSs. Therefore, it is possible to produce not only an environmentally friendly gas but also a gas fraction with a relevant HHV. Finally, there was a noteworthy impact of the feedstock-to-catalyst ratio on $\mathrm{CO}_{2}$ and $\mathrm{H}_{2}$ production. $\mathrm{H}_{2}$ production increased as $\mathrm{CaO}$ increased in the feed, while $\mathrm{CO}_{2}$ was progressively reduced to negligible values and HHV was kept in the same range $(25.6 \mathrm{MJ} / \mathrm{Kg})$. For the highest feedstock-to- $\mathrm{CaO}$ ratio studied, a $\mathrm{CO}_{2}$-free gas fraction was obtained, whereas $\mathrm{H}_{2}$ production was maximized $(63.2$ vol\%). Therefore, these experimental conditions may be considered as a very interesting solution from the environmental perspective.

\subsection{Influence of WTs and $\mathrm{CaO}$ on liquid fuel properties and chemical composition}

The properties of the liquid fuel are compiled in Table 4. The addition of both WTs and $\mathrm{CaO}$ to the feed generally resulted in positive synergistic effects on the physical and chemical properties of the liquid produced. As expected, the incorporation of WTs 
significantly reduced the oxygen content in the bio-oil. Remarkably, these values were lower than those obtained based on the rule of mixtures for WTs percentages higher than $20 \mathrm{wt} \%$ (Table 4, Section B), achieving a deoxygenation rate of 26 and $54 \%$ for 20 and $40 \mathrm{wt} \% \mathrm{WTs}$, respectively. Consequently, a significant increase in heating values of 37.6 and $40.4 \mathrm{MJ} / \mathrm{kg}$ was produced, respectively. Significantly, the synergistic effects on the deoxygenation rates were more apparent when the catalytic co-pyrolysis process was performed (Table 4, section E). The oxygen content in the bio-oil was able to be lowered to values ranging between 9.2 and $4.2 \mathrm{wt} \%$ depending on the WTs content, and remarkable $\mathrm{HHV}$ values of $39.4-41.4 \mathrm{MJ} / \mathrm{kg}$ were consequently obtained. It is worthy of note that these values were quite close to those observed in WTs pyrolytic oils. The oxygen content of the catalytic co-pyrolysis bio-oils implied that the addition of $\mathrm{CaO}$ increased the deoxygenation rate to $30 \%$, in comparison with that found in the conventional co-pyrolysis process. Remarkably, a very low sulphur content $(0.1-0.2$ wt\%) was obtained by catalytic co-pyrolysis compared to that obtained with conventional co-pyrolysis (0.1-0.4 wt. \%), minimizing further environmental policies issues related to the use of these bio-oils as drop-in biofuels. Although the removal of gaseous reactive pollutants mainly depends on the type of reactor, operating conditions and the chemical nature of the adsorbent used [50], it is generally accepted that at atmospheric pressure and relative high temperature, $\mathrm{CaO}$ has the capacity to react with $\mathrm{H}_{2} \mathrm{~S}$ to form $\mathrm{CaS}[51,52]$, which likely limits the formation of sulphur condensable organic compounds. Moreover, it cannot be totally ruled out that the presence of a 419 relevant content of $\mathrm{K}, \mathrm{Na}$ and $\mathrm{Ca}$ salts in the GSs feedstock could also promote sulphur capture [53]. Hence, Table 5 shows evidence of a high proportion of $\mathrm{CaO}$ and $\mathrm{K}_{2} \mathrm{O}$ in the composition of the GSs ash from, while other elements such as P, Si and $\mathrm{Mg}$ are also present at remarkably concentrations. 
423 Additionally, the acidic parameters were also greatly modified. In fact, when $\mathrm{CaO}$ was 424 added to the process, the $\mathrm{pH}$ value substantially increased, ranging from 9 to 10 , while

425 TAN values were lower than $1 \mathrm{mg} \mathrm{KOH} / \mathrm{g}$ in all cases. As a consequence, issues related 426 with the instability and corrosiveness of the bio-oil could be greatly reduced to a great 427 extent.

Table 6 summarizes the chemical composition of the organic layer. It should be pointed out that the organic fraction of the GSs consisted of a mixture of a small fraction of aromatic and paraffinic compounds and a predominant fraction made up of phenols and other oxygenated compounds, and even acids, particularly fatty acids from vegetable oil contained in the seeds [35]. However, the oil produced from the pyrolysis of WTs mainly consisted of aromatics, limonene and other hydrocarbons, such as linear paraffins and cyclic-hydrocarbons. The incorporation of WTs into GSs pyrolysis led to an improved bio-oil in which the production of linear paraffins and cyclic-hydrocarbons significantly increased, particularly as the proportion of WTs in the feedstock was increased, while other valuable biofuel products (aromatics, olefins, ketones and esters) kept fairly constant values. Comparing these results to the theoretical values, noteworthy differences can be observed. A greater production of cyclic-hydrocarbons was achieved, whereas phenol compounds suffered a drastic reduction, more significantly at the highest proportion of WTs studied. At this proportion of WTs, a great increment in linear paraffins was also achieved. On the contrary, there were no apparent differences in the aromatic fraction, which was approximately within the same range at all proportions, and was higher than expected only at lower proportions of WTs. This could be associated with the enhancement of hydro-deoxygenation reactions, 447 favoured by the extra- $\mathrm{H}_{2}$ production after WT incorporation and the relative higher 
temperatures of the process [54]. Accordingly, the main products from the hydrodeoxygenation process $\left(\mathrm{H}_{2} \mathrm{O}, \mathrm{CO}_{2}\right.$ and $\left.\mathrm{CO}\right)$ were kept at relevant high levels (see Tables 2 and 3).

451 When analysing the impact of the catalyst, it should be pointed out that the incorporation of $\mathrm{CaO}$ had different effects when was added to the GSs or WTs pyrolysis, independently. As can be seen in Table 6, section D, CaO incorporation into the GSs feedstock promoted the production of hydrocarbons at the same time as a high reduction in phenols. This can be attributed to the cracking capacity of $\mathrm{CaO}[20]$ and the inherent $\mathrm{CaO}$ effect on $\mathrm{CO}_{2}$ capture and $\mathrm{H}_{2}$ production by water gas shift reaction, favouring hydrogen-transfer reactions from phenols into desired compounds. These compounds included aromatics that could mainly have been produced via the hydrodeoxygenation of phenols, and other hydrocarbons such as cyclic-hydrocarbons (mainly cyclo-alkanes) and olefins that could have been produced via hydrogenation and hydrocracking reactions, respectively [55-57]. These results suggest that not only hydrodeoxygenation reactions but also hydrocracking reactions may have taken place. Moreover, the increment in linear ketones, particularly long-chain ketones (see Table $\mathrm{S} 1$ ), suggests that a decarboxylation reaction was simultaneously taking place via the ketonization pathway. These results are in line with those of other works [20], which describe the effect of $\mathrm{CaO}$ on reducing the levels of phenols while increasing the 467 formation of ketones and several hydrocarbons in catalytic fast pyrolysis. On the other hand, the incorporation of $\mathrm{CaO}$ into the WTs feedstock promoted hydro-cyclization reactions from linear paraffins to cyclic-hydrocarbons, as can be observed in Table 6. Again, the enhancement of $\mathrm{H}_{2}$ production seems to be a key factor for the occurrence of 471 this type of reaction. 
472 With regard to the effect of the $\mathrm{CaO}$ on catalytic co-pyrolysis, a different bio-oil 473 composition was obtained depending on the WTs proportion. As previously mentioned, 474 different upgrading routes may have been occurring simultaneously. At a WTs proportion lower than $20 \mathrm{wt} \%$, the relevant production of ketones and esters compared to those theoretically expected suggested that de-acidification and deoxygenation of the

477 bio-oil through ketonization and esterification reactions prevailed over the aromatization and hydrodeoxygenation routes. As previously reported, metallic oxides including $\mathrm{CaO}$ [58] can promote ketonic decarboxylation. Thus, water formation, one of the main by-products produced by these kinds of reactions jointly with $\mathrm{CO}_{2}$, remained at the highest values (See table 2, Section E).

However the opposite was true when the amount of WTs in the feedstock was $40 \mathrm{wt} \%$, since the content of aromatics, linear paraffins and cyclic-hydrocarbons was higher than those theoretically expected (Table 6, Section E), supporting the key role of the aromatization and hydro-deoxygenation upgrading routes. This fact is in line with both higher $\mathrm{H}_{2} \mathrm{O}$ production than that theoretically calculated for the highest WTs loading, as previously mentioned, and relevant $\mathrm{H}_{2}$ production through both the thermal cracking of plastic-type chains of the WTs (chain-end scission mechanism) and the sorptionenhanced water gas shift process. This extra $\mathrm{H}_{2}$ seemed to be supplied to biomassderived oxygenates, which act as strong acceptors and form more desirable compounds [26]. Phenol hydrodeoxygenation seems to play a fundamental role in the formation of aromatics, particularly owing to the enhancement of $\mathrm{H}_{2}$ production and dehydration reactions. Moreover, due to the enhancement of $\mathrm{H}_{2}$, hydrogen transfer reactions involving aromatics could take place, favouring cyclic-hydrocarbons production. The enhancement of cyclo-alkane production, which was greatly superior to theoretical values, together with the remarkable reduction in ketones, could indicate that a cascade 
of reactions involving the hydrodeoxygenation of ketones to favour cyclic-hydrocarbon production [59] could be taking place. These kinds of reactions actually remove oxygen completely in form of $\mathrm{H}_{2} \mathrm{O}$, as the low oxygen content in the bio-oil and noteworthy water production would indicate.

501

It must be highlighted that when using a WTs content of $40 \mathrm{wt} \%$, it was possible to increase the aromatic production to $27.1 \%$, an increase of approximately $50 \%$ in comparison with a non-catalytic experiment, which was also a significantly higher value than the theoretical one. For this mixture, valuable compounds such as benzene, benzene-derived compounds (mainly ethylbenzene), xylene and D-limonene were greatly enhanced, increasing the potential use of the bio-oil as a drop-in fuel and/or source of chemical products. These findings could have a significant impact on the subsequent application of the liquid. Cyclo-alkanes are main components of jet fuels and can be considered compact molecules within a robust ring strain [60] that can be cleanly burned with high heats of combustion. Thus, the presence of cyclo-alkanes within the range of those used in jet fuels $\left(\mathrm{C}_{8}-\mathrm{C}_{16}\right)$ could be very positive for the use of 512 these liquids as drop-in fuels. In addition, some oxygenated benzene-derived compounds, such as benzyl alcohol and cyclopentyl phenyl methanol, were dramatically

514 reduced (Table 1, SI). Another advantage is that the use of $\mathrm{CaO}$ as catalyst has made it 515 possible to significantly reduce the levels of acids and phenols to very low values $(\sim 1.7$ and $2.5 \%$, respectively) in comparison with those resulting from conventional co517 pyrolysis. These results are in line with the higher $\mathrm{pH}$ values and negligible TAN values 518 achieved.

519 At this point, it is worth mentioning that although the impact of the feedstock-tocatalyst ratio had an important effect on $\mathrm{CO}_{2}$ and $\mathrm{H}_{2}$ production, hydrogen-transfer reactions into desired products such as aromatics and hydrocarbons did not seem to be 
522 maximized. In fact, when using a feedstock-to-CaO ratio of 1 , there was maximum

523 production of both aromatic hydrocarbons and cyclic-hydrocarbons, as well as 524 minimization of the oxygen content that makes bio-oil more suitable for further 525 applications. The latter, jointly with the further economic issues that affect the 526 incorporation of large amounts of catalyst, suggest an optimum feedstock-to-catalyst 527 ratio of 1.

528 A simplified overview of the suggested mechanism reaction for the catalytic co529 pyrolysis process was summarized in Figure 3. Thus, from thermal degradation of 530 cellulose and hemicellulose of GSs several oxygenated compounds, mainly esters and 531 ketones, would be formed through decarbonylation and decarboxylation reactions. On 532 the opposite, phenols would be the main components produced from thermal 533 degradation of lignin. Moreover, fatty acids, characteristic components of GSs, would 534 be transformed into long-chain hydrocarbons through dehydration, decarbonylation, and 535 decarboxylation reactions. The thermal degradation of WTs, that could be divided in 536 styrene-butadiene and polybutadiene, would entail two main routes. First, random 537 scission mechanism where isoprene, butene and styrene would be the main components. 538 Thus, limonene would be the main component produced from isoprene through 539 cyclization reactions [61] whilst a great amount of aromatic hydrocarbons would be 540 formed through a sequence of hydrogenation, aromatization, polymerization and 541 oligomerization reactions. On the other hand, the chain-end scission mechanism would 542 take place simultaneously [26], producing $\mathrm{H}_{2}$ and free radicals that would be 543 transformed into straight chain hydrocarbons via hydrogen transfer reactions. Thus, 544 both the $\mathrm{H}_{2}$ produced from the thermal degradation of WTs and the extra $\mathrm{H}_{2}$ produced 545 by the water gas shift reaction enhanced by $\mathrm{CaO}$ would be added to the biomass-derived 
compounds to promote the production of desired compounds, mainly linear paraffins, aromatics and cyclic hydrocarbons.

548 Finally, it can be noted that the major effect found in the deoxygenation of bio-oil

549 through a hydrocarbon and aromatic-rich liquid produces a direct consequence: 550 improvement in the instant mixture with other conventional liquid fuels such as diesel 551 and gasoline. As shown in Figure 4a, conventional pyrolysis bio-oil does not totally mix 552 with these hydrocarbon fuels. On the other hand, after the catalytic co-pyrolysis process, 553 it is possible to greatly improve the instant mixture with commercial liquid fuels (see 554 Figure $4 \mathrm{~b}$ and Figure $4 \mathrm{c})$.

\subsection{Char characterisation}

Through different mixtures from the conventional co-pyrolysis of GSs and WTs, negligible differences were found regarding the elementary composition and calorific value of the char. The LHV of char obtained from this process was around $27-29 \mathrm{MJ} / \mathrm{kg}$, reaching the highest values as the WTs \% in the feeding rose, as was expected due to the higher fixed $\mathrm{C}$ content in WTs. These values were similar to the LHV of char obtained from the pyrolysis of GSs (27.4 MJ/kg) and slightly inferior in comparison with LHV from WTs pyrolysis alone (30 MJ/kg). Thus, the high energy content, which is higher than that of other solid fuels [62], means that this solid fraction is an attractive alternative for either further combustion processes or to support the energy requirements of the process. In relation to catalytic WTs pyrolysis, one important point covered is the reduction of sulphur content in char compared to the pyrolysis of WTs alone, with this content reduced from $2.5 \mathrm{wt} \%$ to values lower than $0.5 \mathrm{wt} \%$. This result is in line with the desulphuration process promoted by $\mathrm{CaO}$ sorbents, as previously mentioned. With 
regard to catalytic co-pyrolysis, it should be taken into account that solid inventory was increased. Although the calorific values of the separated char remained at the same levels, LHV was reduced per g of total solid (char + catalyst). As a positive point, sulphur content reduction was enhanced by the catalytic process, reaching values as low

574 as $0.1 \mathrm{wt} \%$ in all cases.

\section{Conclusions}

576

577 In this work, the catalytic co-pyrolysis process of GSs and WTs using $\mathrm{CaO}$ as a catalyst 578 was successfully carried out in a specific-designed fixed-bed reactor. The results reveal 579 that it is possible to obtain a valuable and potentially stable drop-in fuel in a relative simple step. More specifically, the addition of considerable amounts of WTs (between 20 and $40 \mathrm{wt} \%$ ) with a feedstock-to- $\mathrm{CaO}$ ratio fixed at 1 can be considered the optimum experimental conditions to promote positive synergistic effects on bio-oil yields and fuel characteristics. In fact, when WTs in the feed reaches $40 \mathrm{wt} \%$, not only is a significant maximization of aromatic hydrocarbon production achieved, but the liquid is found to have minimum oxygen content, conferring it more potential stability. Moreover, sulphur content is drastically reduced, in comparison with the pyrolysis of WTs alone. The role of $\mathrm{CaO}$ is directly connected with the promotion of dehydration reactions of acids and phenols to produce hydrocarbons. Finally, due to the $\mathrm{CO}_{2}$-capture effect associated with $\mathrm{CaO}$, it is possible to obtain a more environmentally friendly gas that retains its calorific value. 
597 The authors would like to thank MINECO and FEDER for their financial support (Project

598 ENE2015-68320-R). The authors would also like to thank the Regional Government of Aragon

599 (DGA) for the support provided under the research groups support programme.

600

601

\section{References}

602

603

604

605

606

607

608

609

610

611

612

613

614

615

616

617

618

619

620

621

622

623

624

625

626

627

628

629

630

631

632

633

634

635

636

637

638

1. Isikgor, F.H. and C.R. Becer, Lignocellulosic biomass: a sustainable platform for the production of bio-based chemicals and polymers. Polymer Chemistry, 2015. 6(25): p.

4497-4559.

2. Sharma, A., V. Pareek, and D. Zhang, Biomass pyrolysis-A review of modelling, process parameters and catalytic studies. Renewable and Sustainable Energy Reviews, 2015. 50: p. 1081-1096.

3. Strezov, V., T.J. Evans, and C. Hayman, Thermal conversion of elephant grass (Pennisetum Purpureum Schum) to bio-gas, bio-oil and charcoal. Bioresource Technology, 2008. 99(17): p. 8394-8399.

4. Hossain, A.K. and P.A. Davies, Pyrolysis liquids and gases as alternative fuels in internal combustion engines - A review. Renewable and Sustainable Energy Reviews, 2013. 21: p. 165-189.

5. Veses, A., et al., An integrated process for the production of lignocellulosic biomass pyrolysis oils using calcined limestone as a heat carrier with catalytic properties. Fuel, 2016. 181: p. 430-437.

6. Yildiz, G., et al., Challenges in the design and operation of processes for catalytic fast pyrolysis of woody biomass. Renewable and Sustainable Energy Reviews, 2016. 57: p. 1596-1610.

7. Mohan, D., C.U. Pittman Jr, and P.H. Steele, Pyrolysis of wood/biomass for bio-oil: $A$ critical review. Energy and Fuels, 2006. 20(3): p. 848-889.

8. Bridgwater, A.V., Renewable fuels and chemicals by thermal processing of biomass. Chemical Engineering Journal, 2003. 91(2-3): p. 87-102.

9. Guedes, R.E., A.S. Luna, and A.R. Torres, Operating parameters for bio-oil production in biomass pyrolysis: A review. Journal of Analytical and Applied Pyrolysis, 2018. 129: $p$. 134-149.

10. Dhyani, V. and T. Bhaskar, A comprehensive review on the pyrolysis of lignocellulosic biomass. Renewable Energy, 2017.

11. Wang, S., et al., Lignocellulosic biomass pyrolysis mechanism: A state-of-the-art review. Progress in Energy and Combustion Science, 2017. 62: p. 33-86.

12. Huber, G.W. and A. Corma, Synergies between bio- and oil refineries for the production of fuels from biomass. Angewandte Chemie - International Edition, 2007. 46(38): p. 7184-7201.

13. Talmadge, M.S., et al., A perspective on oxygenated species in the refinery integration of pyrolysis oil. Green Chemistry, 2014. 16(2): p. 407-453.

14. Stefanidis, S.D., K.G. Kalogiannis, and A.A. Lappas, Co-processing bio-oil in the refinery for drop-in biofuels via fluid catalytic cracking. WIREs Energy and Environmental, 2017. e281. 
15. Bridgwater, A.V., Review of fast pyrolysis of biomass and product upgrading. Biomass and Bioenergy, 2012. 38: p. 68-94.

16. Fermoso, J., et al., Advanced biofuels production by upgrading of pyrolysis bio-oil. Wiley Interdisciplinary Reviews: Energy and Environment, 2017. 6(4).

17. Grac̀a, I., et al., Bio-oils upgrading for second generation biofuels. Industrial and Engineering Chemistry Research, 2013. 52(1): p. 275-287.

18. Veses, A., et al., Production of upgraded bio-oils by biomass catalytic pyrolysis in an auger reactor using low cost materials. Fuel, 2015. 141: p. 17-22.

19. Veses, A., et al., Catalytic pyrolysis of wood biomass in an auger reactor using calciumbased catalysts. Bioresource Technology, 2014. 162: p. 250-258.

20. Lu, Q., et al., Catalytic Upgrading of Biomass Fast Pyrolysis Vapors with Nano Metal Oxides: An Analytical Py-GC/MS Study. Energies, 2010. 3(11): p. 1805-1820.

21. Kelkar, S., et al., A survey of catalysts for aromatics from fast pyrolysis of biomass. Applied Catalysis B: Environmental, 2015. 174-175: p. 85-95.

22. Cao, Q., et al., Investigations into the characteristics of oils produced from co-pyrolysis of biomass and tire. Fuel Processing Technology, 2009. 90(3): p. 337-342.

23. Martínez, J.D., et al., Co-pyrolysis of biomass with waste tyres: Upgrading of liquid biofuel. Fuel Processing Technology, 2014. 119: p. 263-271.

24. Xue, Y., et al., Fast pyrolysis of biomass and waste plastic in a fluidized bed reactor. Fuel, 2015. 156: p. 40-46.

25. Dorado, C., C.A. Mullen, and A.A. Boateng, H-ZSM5 catalyzed co-pyrolysis of biomass and plastics. ACS Sustainable Chemistry and Engineering, 2014. 2(2): p. 301-311.

26. Zhang, X., et al., Catalytic co-pyrolysis of lignocellulosic biomass with polymers: $A$ critical review. Green Chemistry, 2016. 18(15): p. 4145-4169.

27. Abnisa, F. and W.M.A. Wan Daud, A review on co-pyrolysis of biomass: An optional technique to obtain a high-grade pyrolysis oil. Energy Conversion and Management, 2014. 87: p. 71-85.

28. Hassan, H., J.K. Lim, and B.H. Hameed, Recent progress on biomass co-pyrolysis conversion into high-quality bio-oil. Bioresource Technology, 2016. 221: p. 645-655.

29. Kabir, G. and B.H. Hameed, Recent progress on catalytic pyrolysis of lignocellulosic biomass to high-grade bio-oil and bio-chemicals. Renewable and Sustainable Energy Reviews, 2017. 70: p. 945-967.

30. Uzoejinwa, B.B., et al., Co-pyrolysis of biomass and waste plastics as a thermochemical conversion technology for high-grade biofuel production: Recent progress and future directions elsewhere worldwide. Energy Conversion and Management, 2018. 163: p. 468-492.

31. Yao, W., et al., Thermally stable phosphorus and nickel modified ZSM-5 zeolites for catalytic co-pyrolysis of biomass and plastics. RSC Advances, 2015. 5(39): p. 3048530494.

32. Li, J., et al., Maximizing carbon efficiency of petrochemical production from catalytic co-pyrolysis of biomass and plastics using gallium-containing MFI zeolites. Applied Catalysis B: Environmental, 2015. 172-173: p. 154-164.

33. Rezaei, P.S., et al., In-situ catalytic co-pyrolysis of yellow poplar and high-density polyethylene over mesoporous catalysts. Energy Conversion and Management, 2017. 151: p. 116-122.

34. $\mathrm{Xu}, \mathrm{R}$. , et al., Flash pyrolysis of grape residues into biofuel in a bubbling fluid bed. Journal of Analytical and Applied Pyrolysis, 2009. 86(1): p. 58-65.

35. Brebu, M., et al., Thermal and catalytic degradation of grape seeds/polyethylene waste mixture. Vol. 48. 2014. 665-674.

36. Martínez, J.D., et al., Demonstration of the waste tire pyrolysis process on pilot scale in a continuous auger reactor. Journal of Hazardous Materials, 2013. 261: p. 637-645. 
37. Edwin Raj, R., Z. Robert Kennedy, and B.C. Pillai, Optimization of process parameters in flash pyrolysis of waste tyres to liquid and gaseous fuel in a fluidized bed reactor. Energy Conversion and Management, 2013. 67: p. 145-151.

38. Martínez, J.D., et al., Waste tyre pyrolysis - A review. Renewable and Sustainable Energy Reviews, 2013. 23: p. 179-213.

39. Abnisa, F. and W.M.A. Wan Daud, Optimization of fuel recovery through the stepwise co-pyrolysis of palm shell and scrap tire. Energy Conversion and Management, 2015. 99: p. 334-345.

40. Cabeza, A., et al., Autocatalytic kinetic model for thermogravimetric analysis and composition estimation of biomass and polymeric fractions. Fuel, 2015. 148: p. 212225.

41. Aylón, E., et al., Assessment of tire devolatilization kinetics. Journal of Analytical and Applied Pyrolysis, 2005. 74(1): p. 259-264.

42. Murillo, R., et al., The application of thermal processes to valorise waste tyre. Fuel Processing Technology, 2006. 87(2): p. 143-147.

43. Williams, P.T. and S. Besler, Pyrolysis-thermogravimetric analysis of tyres and tyre components. Fuel, 1995. 74(9): p. 1277-1283.

44. Seidelt, S., M. Müller-Hagedorn, and H. Bockhorn, Description of tire pyrolysis by thermal degradation behaviour of main components. Journal of Analytical and Applied Pyrolysis, 2006. 75(1): p. 11-18.

45. Carpenter, D., et al., Biomass feedstocks for renewable fuel production: A review of the impacts of feedstock and pretreatment on the yield and product distribution of fast pyrolysis bio-oils and vapors. Green Chemistry, 2014. 16(2): p. 384-406.

46. Lin, Y., et al., Deoxygenation of bio-oil during pyrolysis of biomass in the presence of $\mathrm{CaO}$ in a fluidized-bed reactor. Energy and Fuels, 2010. 24(10): p. 5686-5695.

47. Han, C. and D.P. Harrison, Simultaneous shift reaction and carbon dioxide separation for the direct production of hydrogen. Chemical Engineering Science, 1994. 49(24, Part 2): p. 5875-5883.

48. Martínez, l., et al., Review and research needs of Ca-Looping systems modelling for post-combustion $\mathrm{CO} 2$ capture applications. International Journal of Greenhouse Gas Control, 2016. 50: p. 271-304.

49. Rezaei, P.S., H. Shafaghat, and W.M.A.W. Daud, Production of green aromatics and olefins by catalytic cracking of oxygenate compounds derived from biomass pyrolysis: A review. Applied Catalysis A: General, 2014. 469: p. 490-511.

50. Mohanty, C.R., S. Adapala, and B.C. Meikap, Removal of hazardous gaseous pollutants from industrial flue gases by a novel multi-stage fluidized bed desulfurizer. Journal of Hazardous Materials, 2009. 165(1): p. 427-434.

51. Liu, Y., J.L. Morrison, and A.W. Scaroni, Sulfur capture capacity of limestones in combustion gases: Effect of thermally induced cracking. Fuel and Energy Abstracts, 1995. 36(3): p. 220.

52. Altindag, H., Y. Gogebakan, and N. Selçuk, Sulfur capture for fluidized-bed combustion of high-sulfur content lignites. Applied Energy, 2004. 79(4): p. 403-424.

53. Pedersen, L.S., et al., Full-scale co-firing of straw and coal. Fuel, 1996. 75(13): p. 15841590.

54. Cheng, S., et al., Hydrodeoxygenation upgrading of pine sawdust bio-oil using zinc metal with zero valency. Journal of the Taiwan Institute of Chemical Engineers, 2017. 74: p. 146-153.

55. Zhang, X. and H. Lei, Synthesis of high-density jet fuel from plastics via catalytically integral processes. RSC Advances, 2016. 6(8): p. 6154-6163.

56. Zhang, X., et al., From lignocellulosic biomass to renewable cycloalkanes for jet fuels. Green Chemistry, 2015. 17(10): p. 4736-4747. 
757

758

759

760

761

762

763

764

765

766

767

768

769

57. Chuck, C.J. and J. Donnelly, The compatibility of potential bioderived fuels with Jet A-1 aviation kerosene. Applied Energy, 2014. 118: p. 83-91.

58. Hussmann, G.P., (Amoco Corp.), US4754074A. 1988.

59. Corma, A., M. Renz, and C. Schaverien, Coupling Fatty Acids by Ketonic Decarboxylation Using Solid Catalysts for the Direct Production of Diesel, Lubricants, and Chemicals. ChemSusChem, 2008. 1(8-9): p. 739-741.

60. Meylemans, H.A., et al., Solvent-free conversion of linalool to methylcyclopentadiene dimers: A route to renewable high-density fuels. ChemSusChem, 2011. 4(4): p. 465469.

61. Mastral, A.M., et al., Influence of Process Variables on Oils from Tire Pyrolysis and Hydropyrolysis in a Swept Fixed Bed Reactor. Energy \& Fuels, 2000. 14(4): p. 739-744.

62. Parr, S.W., The Classification of Coal. Industrial and Engineering Chemistry, 1922. 14(10): p. 919-922. 

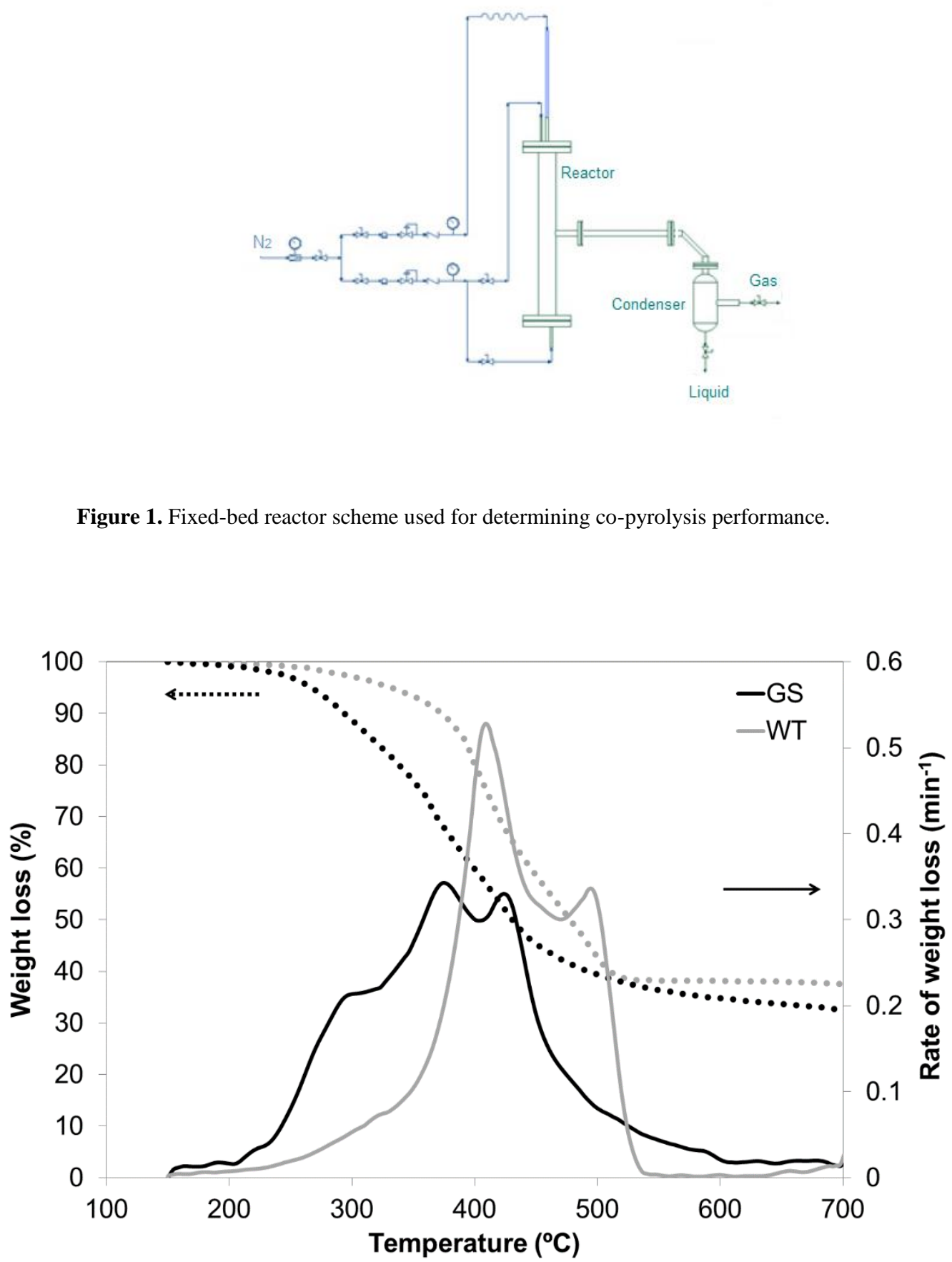

Figure 2. Experimental results of weight loss (dotted lines) and rate of mass loss (solid lines) from the 
WASTE TYRES

GRAPE SEEDS

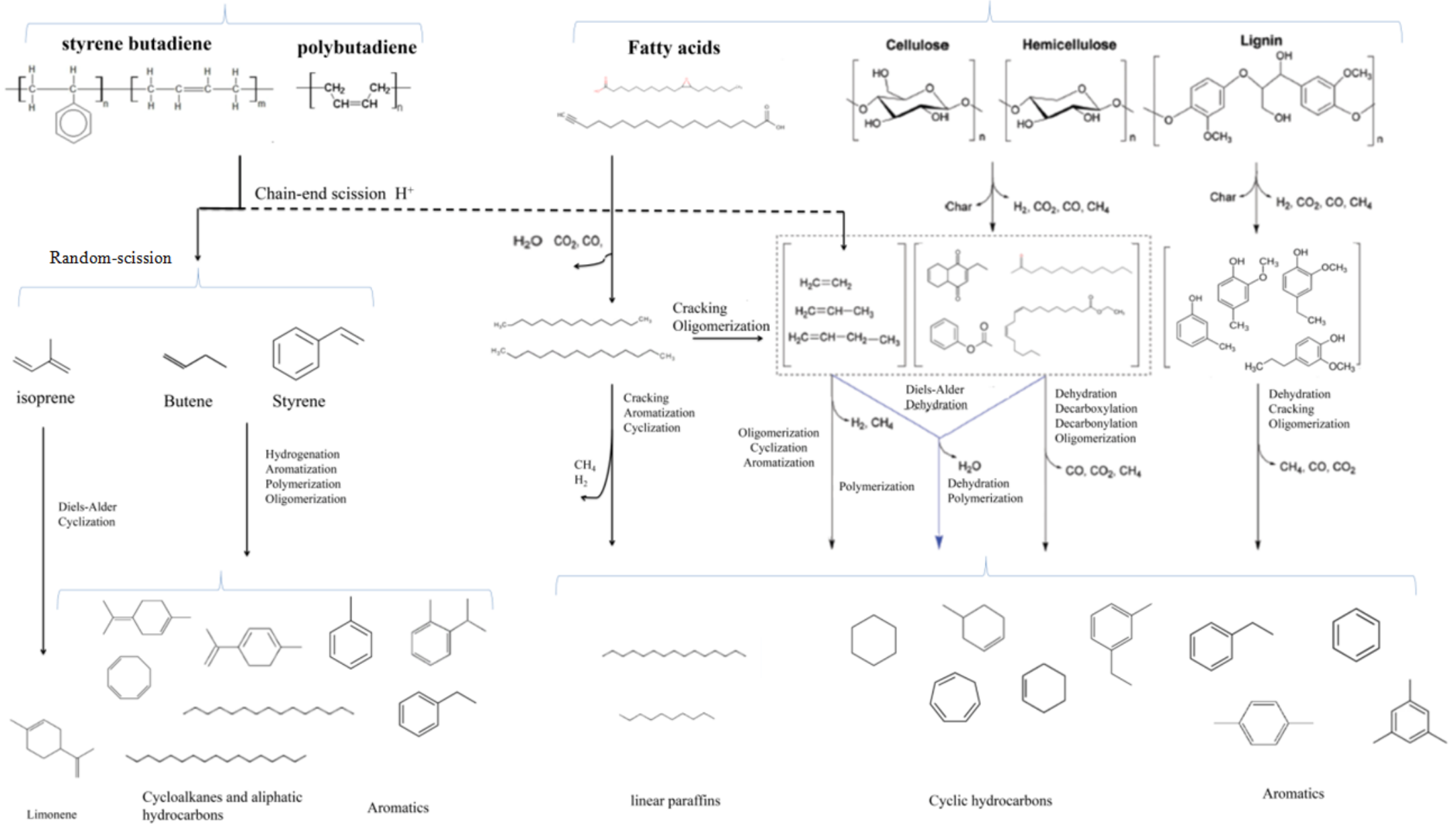

Figure 3. Simplified reaction mechanism proposed for the catalytic co-pyrolysis of GSs and WTs using CaO (adapted from [26, 64]). The main components attending to GC/MS characterization were reflected. 


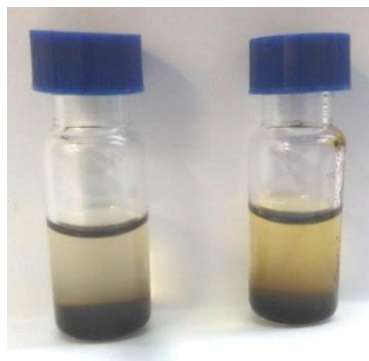

b.

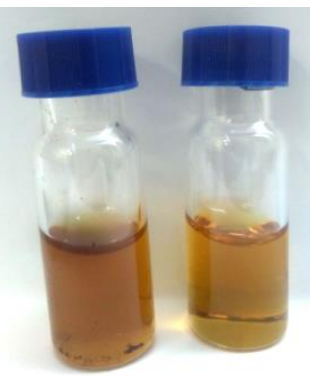

c.

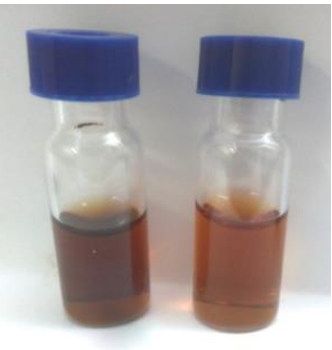

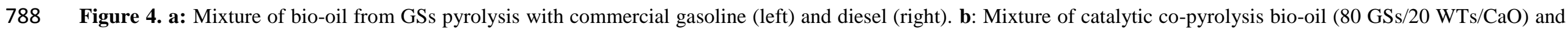


799 Table 1. Feedstock (grape seeds and waste tyres) characterization .

\begin{tabular}{lccc}
\hline & \multicolumn{2}{c}{ Grape seeds } & Waste tyrę0 \\
\cline { 2 - 4 } & Air-dried basis & Dry & Air-dried basis \\
\hline Ash (wt\%) & $4.3 \pm 0.1$ & $4.6 \pm 0.1$ & $3.8 \pm 0.1$ \\
Volatile matter (wt\%) & $65.1 \pm 0.2$ & $69.5 \pm 0.2$ & $63.6 \pm 0.801$ \\
Fixed Carbon (wt\%) & $24.3 \pm 0.2$ & $25.9 \pm 0.2$ & $31.8 \pm 0.1$ \\
Ultimate & & & 802 \\
analysis (wt\%) & & & \\
C & & & \\
H & $53.9 \pm 0.1$ & $57.6 \pm 0.2$ & $87.9 \pm 0.203$ \\
N & $6.6 \pm 0.1$ & $6.3 \pm 0.1$ & $7.4 \pm 0.1$ \\
S & $2.2 \pm 0.1$ & $2.4 \pm 0.1$ & $0.3 \pm 0.1$ \\
O & $0.1 \pm 0.1$ & $0.2 \pm 0.1$ & $1.1 \pm 0.1804$ \\
HHV (MJ/kg) & $37.2 \pm 0.2$ & $33.7 \pm 0.1$ & $3.3 \pm 0.1$ \\
LHV (MJ/kg) & $22.1 \pm 0.1$ & $23.5 \pm 0.1$ & $38.6 \pm 0.805$ \\
& $20.5 \pm 0.1$ & $22.2 \pm 0.1$ & $37.0 \pm 0.1$ \\
\hline
\end{tabular}

HHV: Higher heating value; LHV: Lower heating value; C: Carbon; H: Hydrogen; N: Nitrogen; S: Sulphur; O: Oxygen ': By difference 
Table 2. Product yields (liquid - organic and aqueous phases - solid and gas) in wt $\%$ after conventional pyrolysis and co-pyrolysis of GSs and WTs, and catalytic pyrolysis and co-pyrolysis of GSs and WTs with $\mathrm{CaO}$.

\begin{tabular}{|c|c|c|c|c|c|c|c|}
\hline \multirow{3}{*}{ Section } & \multicolumn{4}{|l|}{ Experiment } & \multicolumn{3}{|c|}{ Yields (wt\%) } \\
\hline & \multirow{2}{*}{$\begin{array}{c}\text { GSs/WTs } \\
(\mathbf{w t} \%)\end{array}$} & \multicolumn{3}{|c|}{ Liquid } & \multirow{2}{*}{ Solid } & \multirow{2}{*}{$\operatorname{Gas}^{1}$} & \multirow{2}{*}{ Total } \\
\hline & & Total & Org. & Aq. & & & \\
\hline \multirow{3}{*}{ A. Conventional pyrolysis } & $100 / 0$ & $38.8 \pm 0.2$ & $61.1 \pm 0.2$ & $38.9 \pm 0.2$ & $33.4 \pm 0.1$ & $23.9 \pm 0.4$ & $96.1 \pm 0.3$ \\
\hline & $0 / 100$ & $43.7 \pm 0.3$ & $100.0 \pm 0.0$ & $0.0 \pm 0.0$ & $37.6 \pm 0.2$ & $14.9 \pm 0.3$ & $96.0 \pm 0.4$ \\
\hline & $95 / 5$ & $40.3 \pm 0.2$ & $58.8 \pm 0.2$ & $41.2 \pm 0.1$ & $32.4 \pm 0.1$ & $23.5 \pm 0.4$ & $96.2 \pm 0.5$ \\
\hline \multirow{3}{*}{ B. Co-pyrolysis of GSs and WTs } & $90 / 10$ & $39.8 \pm 0.1$ & $59.8 \pm 0.2$ & $40.2 \pm 0.1$ & $32.6 \pm 0.1$ & $25.4 \pm 0.4$ & $97.8 \pm 0.5$ \\
\hline & $80 / 20$ & $39.5 \pm 0.1$ & $66.2 \pm 0.2$ & $33.8 \pm 0.1$ & $33.0 \pm 0.1$ & $26.0 \pm 0.5$ & $98.5 \pm 0.3$ \\
\hline & $60 / 40$ & $39.3 \pm 0.1$ & $77.4 \pm 0.1$ & $22.6 \pm 0.1$ & $33.8 \pm 0.1$ & $22.9 \pm$ & $96.0 \pm 0.3$ \\
\hline \multirow[t]{4}{*}{ C. Theoretical co-pyrolysis of GSs and WTs ${ }^{2}$} & $95 / 5$ & $39.0 \pm 0.1$ & $62.9 \pm 0.1$ & $37.1 \pm 0.1$ & $33.6 \pm 0.1$ & $23.5 \pm 0.3$ & --- \\
\hline & $90 / 10$ & $39.3 \pm 0.2$ & $64.9 \pm 0.1$ & $35.1 \pm 0.2$ & $33.8 \pm 0.2$ & $25.4 \pm 0.3$ & --- \\
\hline & $80 / 20$ & $39.8 \pm 0.1$ & $68.8 \pm 0.1$ & $31.2 \pm 0.1$ & $34.2 \pm 0.1$ & $22.1 \pm 0.4$ & --- \\
\hline & $60 / 40$ & $40.7 \pm 0.4$ & $76.6 \pm 0.2$ & $23.4 \pm 0.2$ & $35.1 \pm 0.1$ & $20.3 \pm 0.3$ & --- \\
\hline \multicolumn{8}{|l|}{ Catalytic reactions } \\
\hline \multirow{2}{*}{ D. Catalytic pyrolysis. Feedstock: $\mathrm{CaO}$ 1: 1} & $100 / 0$ & $38.5 \pm 0.2$ & $56.0 \pm 0.2$ & $44.0 \pm 0.1$ & $42.5 \pm 0.2$ & $14.0 \pm 0.2$ & $95.0 \pm 0.5$ \\
\hline & $0 / 100$ & $46.5 \pm 0.4$ & $100.0 \pm 0.0$ & $0.0 \pm 0.0$ & $35.0 \pm 0.1$ & $15.3 \pm 0.3$ & $96.8 \pm 0.3$ \\
\hline \multirow{4}{*}{ E. Catalytic co-pyrolysis of GSs and WTs. Feedstock: CaO 1:1 } & $95 / 5$ & $41.2 \pm 0.3$ & $56.3 \pm 0.2$ & $43.7 \pm 0.1$ & $40.0 \pm 0.1$ & $14.3 \pm 0.2$ & $95.5 \pm 0.6$ \\
\hline & $90 / 10$ & $42.8 \pm 0.2$ & $57.3 \pm 0.1$ & $42.7 \pm 0.1$ & $40.2 \pm 0.1$ & $14.1 \pm 0.4$ & $97.0 \pm 0.6$ \\
\hline & $80 / 20$ & $43.8 \pm 0.3$ & $55.4 \pm 0.1$ & $44.6 \pm 0.2$ & $40.2 \pm 0.1$ & $15.6 \pm 0.3$ & $94.6 \pm 0.3$ \\
\hline & $60 / 40$ & $44.0 \pm 0.3$ & $60.7 \pm 0.2$ & $39.3 \pm 0.1$ & $39.0 \pm 0.1$ & $15.3 \pm 0.4$ & $98.3 \pm 0.4$ \\
\hline \multirow{4}{*}{ F. Theoretical catalytic co-pyrolysis of GSs and WTs ${ }^{3}$} & $95 / 5$ & $38.9 \pm 0.2$ & $58.2 \pm 0.1$ & $41.8 \pm 0.2$ & $42.1 \pm 0.2$ & $14.1 \pm 0.3$ & --- \\
\hline & $90 / 10$ & $39.3 \pm 0.2$ & $60.4 \pm 0.2$ & $39.6 \pm 0.1$ & $41.8 \pm 0.2$ & $14.1 \pm 0.3$ & --- \\
\hline & $80 / 20$ & $40.1 \pm 0.2$ & $64.8 \pm 0.2$ & $35.2 \pm 0.1$ & $41.0 \pm 0.2$ & $14.3 \pm 0.2$ & --- \\
\hline & $60 / 40$ & $41.7 \pm 0.4$ & $73.6 \pm 0.2$ & $26.4 \pm 0.1$ & $39.5 \pm 0.1$ & $14.5 \pm 0.4$ & --- \\
\hline \multirow{4}{*}{ G. Variable Feedstock/CaO ratio (in brackets) } & $80 / 20(3: 1)$ & $38.0 \pm 0.2$ & $52.7 \pm 0.1$ & $47.3 \pm 0.2$ & $38.8 \pm 0.1$ & $18.6 \pm 0.5$ & $95.4 \pm 0.3$ \\
\hline & $80 / 20(2: 1)$ & $41.2 \pm 0.3$ & $65.2 \pm 0.1$ & $34.8 \pm 0.2$ & $42.2 \pm 0.2$ & $12.5 \pm 0.5$ & $95.9 \pm 0.6$ \\
\hline & $80 / 20(1: 1)$ & $43.8 \pm 0.4$ & $55.4 \pm 0.1$ & $44.6 \pm 0.2$ & $40.2 \pm 0.2$ & $15.6 \pm 0.3$ & $94.6 \pm 0.5$ \\
\hline & $80 / 20(1: 2)$ & $49.5 \pm 0.3$ & $42.0 \pm 0.1$ & $58.0 \pm 0.2$ & $35.0 \pm 0.1$ & $13.0 \pm 0.4$ & $97.5 \pm 0.4$ \\
\hline
\end{tabular}


Table 3. Gas composition in vol\% after conventional pyrolysis of GSs and WTs, co-pyrolysis of GSs and WTs, catalytic pyrolysis of GSs and WTs and catalytic co-pyrolysis of GSs and WTs.

\begin{tabular}{|c|c|c|c|c|c|c|c|c|c|}
\hline & \multicolumn{4}{|l|}{ Experiment } & \multicolumn{5}{|c|}{ Gas analysis (vol\%) } \\
\hline & $\begin{array}{l}\text { GSs/WTs } \\
(w t \%)\end{array}$ & $\mathbf{H}_{2}$ & $\mathrm{CO}$ & $\mathrm{CO}_{2}$ & $\mathbf{C H}_{4}$ & $\mathbf{C}_{2} \mathbf{H}_{6}$ & $\mathbf{C}_{2} \mathbf{H}_{4}$ & $\begin{array}{l}\text { Higher } \\
\text { HCs }\end{array}$ & $\begin{array}{c}\text { HHV } \\
\left(\mathbf{M J} / \mathbf{N m}^{3}\right)\end{array}$ \\
\hline A. Conventional pyrolysis & $\begin{array}{l}100 / 0 \\
0 / 100\end{array}$ & $\begin{array}{l}18.1 \pm 0.5 \\
28.9 \pm 0.4\end{array}$ & $\begin{array}{l}22.8 \pm 0.5 \\
4.1 \pm 0.2\end{array}$ & $\begin{array}{l}38.8 \pm 0.9 \\
6.2 \pm 0.5\end{array}$ & $\begin{array}{l}12.8 \pm 0.4 \\
15.9 \pm 0.5\end{array}$ & $\begin{array}{l}3.4 \pm 0.4 \\
9.6 \pm 0.4\end{array}$ & $\begin{array}{l}1.0 \pm 0.4 \\
7.4 \pm 0.4\end{array}$ & $\begin{array}{c}2.2 \pm 0.5 \\
27.7 \pm 0.9\end{array}$ & $\begin{array}{l}15.3 \pm 0.5 \\
49.3 \pm 1.1\end{array}$ \\
\hline B. Co-pyrolysis of GSs and WTs & $\begin{array}{c}95 / 5 \\
90 / 10 \\
80 / 20 \\
60 / 40\end{array}$ & $\begin{array}{l}21.2 \pm 0.5 \\
21.1 \pm 0.6 \\
22.0 \pm 0.5 \\
21.4 \pm 0.4\end{array}$ & $\begin{array}{l}19.9 \pm 0.5 \\
18.9 \pm 0.7 \\
16.8 \pm 0.5 \\
15.6 \pm 0.5\end{array}$ & $\begin{array}{l}37.5 \pm 0.8 \\
36.3 \pm 0.7 \\
30.6 \pm 0.7 \\
26.4 \pm 0.5\end{array}$ & $\begin{array}{l}14.2 \pm 0.5 \\
13.1 \pm 0.6 \\
14.8 \pm 0.5 \\
15.2 \pm 0.6\end{array}$ & $\begin{array}{l}3.0 \pm 0.4 \\
3.3 \pm 0.4 \\
3.7 \pm 0.4 \\
3.1 \pm 0.4\end{array}$ & $\begin{array}{l}0.4 \pm 0.3 \\
1.1 \pm 0.6 \\
2.6 \pm 0.5 \\
4.6 \pm 0.5\end{array}$ & $\begin{array}{c}3.4 \pm 0.4 \\
6.3 \pm 0.5 \\
8.6 \pm 0.5 \\
13.5 \pm 0.7\end{array}$ & $\begin{array}{l}16.4 \pm 0.4 \\
19.4 \pm 0.5 \\
23.5 \pm 0.7 \\
29.3 \pm 0.8\end{array}$ \\
\hline C. Theoretical co-pyrolysis of GSs and WTs ${ }^{12}$ & $\begin{array}{c}95 / 5 \\
90 / 10 \\
80 / 20 \\
60 / 40\end{array}$ & $\begin{array}{l}18.6 \pm 0.5 \\
19.2 \pm 0.5 \\
20.3 \pm 0.7 \\
22.4 \pm 0.4\end{array}$ & $\begin{array}{l}21.9 \pm 0.7 \\
20.9 \pm 0.6 \\
19.1 \pm 0.5 \\
15.3 \pm 0.5\end{array}$ & $\begin{array}{l}37.2 \pm 0.6 \\
35.5 \pm 0.8 \\
32.3 \pm 0.7 \\
25.8 \pm 0.5\end{array}$ & $\begin{array}{l}13.0 \pm 0.5 \\
13.1 \pm 0.4 \\
13.4 \pm 0.5 \\
14.0 \pm 0.5\end{array}$ & $\begin{array}{l}3.7 \pm 0.4 \\
4.0 \pm 0.4 \\
4.6 \pm 0.5 \\
5.9 \pm 0.5\end{array}$ & $\begin{array}{l}1.3 \pm 0.3 \\
1.6 \pm 0.5 \\
2.3 \pm 0.4 \\
3.6 \pm 0.4\end{array}$ & $\begin{array}{c}3.5 \pm 0.3 \\
4.8 \pm 0.3 \\
7.3 \pm 0.5 \\
12.4 \pm 0.5\end{array}$ & $\begin{array}{l}17.0 \pm 0.5 \\
18.7 \pm 0.5 \\
22.1 \pm 0.6 \\
28.9 \pm 0.6\end{array}$ \\
\hline Catalytic reactions & & & & & & & & & \\
\hline D. Catalytic pyrolysis. Feedstock: $\mathrm{CaO} 1: 1$ & $\begin{array}{l}100 / 0 \\
0 / 100\end{array}$ & $\begin{array}{l}49.9 \pm 1.1 \\
35.3 \pm 1.0\end{array}$ & $\begin{array}{c}15.8 \pm 0.5 \\
0.3 \pm 0.1\end{array}$ & $\begin{array}{l}6.3 \pm 0.5 \\
0.7 \pm 0.2\end{array}$ & $\begin{array}{l}14.5 \pm 0.6 \\
17.0 \pm 0.6\end{array}$ & $\begin{array}{l}6.3 \pm 0.5 \\
9.0 \pm 0.4\end{array}$ & $\begin{array}{l}2.7 \pm 0.4 \\
7.6 \pm 0.5\end{array}$ & $\begin{array}{l}4.4 \pm 0.4 \\
30 \pm 1.1\end{array}$ & $\begin{array}{l}24.3 \pm 0.7 \\
52.0 \pm 1.1\end{array}$ \\
\hline $\begin{array}{l}\text { E. Catalytic co-pyrolysis of GSs and WTs. } \\
\text { Feedstock: } \mathrm{CaO} 1: 1\end{array}$ & $\begin{array}{l}95 / 5 \\
90 / 10 \\
80 / 20 \\
60 / 40\end{array}$ & $\begin{array}{c}54.3 \pm 1.1 \\
57.8 \pm 1.2 \\
54.3 \pm 1.1 \\
57.2 \pm 1.2\end{array}$ & $\begin{array}{l}14.4 \pm 0.5 \\
12.7 \pm 0.5 \\
14.4 \pm 0.6 \\
10.2 \pm 0.5\end{array}$ & $\begin{array}{l}3.6 \pm 0.4 \\
1.6 \pm 0.4 \\
3.6 \pm 0.5 \\
1.1 \pm 0.5\end{array}$ & $\begin{array}{l}15.1 \pm 0.6 \\
17.4 \pm 0.6 \\
15.1 \pm 0.6 \\
17.4 \pm 0.6\end{array}$ & $\begin{array}{l}3.2 \pm 0.5 \\
3.3 \pm 0.5 \\
3.2 \pm 0.5 \\
4.7 \pm 0.6\end{array}$ & $\begin{array}{l}2.7 \pm 0.5 \\
1.7 \pm 0.5 \\
2.7 \pm 0.5 \\
1.7 \pm 0.5\end{array}$ & $\begin{array}{l}6.7 \pm 0.5 \\
5.4 \pm 0.6 \\
2.6 \pm 0.6 \\
7.6 \pm 0.7\end{array}$ & $\begin{array}{l}25.3 \pm 0.8 \\
24.6 \pm 0.6 \\
25.8 \pm 0.8 \\
27.2 \pm 0.7\end{array}$ \\
\hline $\begin{array}{l}\text { F. Theoretical catalytic co-pyrolysis of GSs and } \\
\text { WTs }{ }^{2} \text {. Feedstock: CaO 1:1 }\end{array}$ & $\begin{array}{c}95 / 5 \\
90 / 10 \\
80 / 20 \\
60 / 40\end{array}$ & $\begin{array}{c}49.2 \pm 0.9 \\
48.4 \pm 0.9 \\
47.0 \pm 1.1 \\
44.1 \pm 1.2\end{array}$ & $\begin{array}{c}15.0 \pm 0.5 \\
14.3 \pm 0.5 \\
12.7 \pm 0.5 \\
9.6 \pm 0.6\end{array}$ & $\begin{array}{l}6.0 \pm 0.5 \\
5.7 \pm 0.6 \\
5.2 \pm 0.6 \\
4.1 \pm 0.5\end{array}$ & $\begin{array}{c}14.6 \pm 0.8 \\
14.8 \pm 0.6 \\
15.0 \pm 0.7 \\
15.5 \pm 0.8\end{array}$ & $\begin{array}{l}6.4 \pm 0.5 \\
6.6 \pm 0.6 \\
6.8 \pm 0.6 \\
7.4 \pm 0.8\end{array}$ & $\begin{array}{l}2.9 \pm 0.5 \\
3.2 \pm 0.6 \\
3.7 \pm 0.8 \\
4.7 \pm 0.8\end{array}$ & $\begin{array}{c}5.7 \pm 0.8 \\
7.0 \pm 0.8 \\
9.5 \pm 0.8 \\
14.6 \pm 0.6\end{array}$ & $\begin{array}{l}25.7 \pm 1.1 \\
27.1 \pm 1.2 \\
29.8 \pm 1.0 \\
35.4 \pm 1.0\end{array}$ \\
\hline $\begin{array}{l}\text { G. Catalytic co-pyrolysis of GSs and WTs. } \\
\text { Variable Feedstock: } \mathrm{CaO} \text { (in brackets) }\end{array}$ & $\begin{array}{l}80 / 20(3: 1) \\
80 / 20(2: 1) \\
80 / 20(1: 1) \\
80 / 20(1: 2)\end{array}$ & $\begin{array}{l}46.8 \pm 0.9 \\
47.4 \pm 1.1 \\
54.3 \pm 0.8 \\
63.2 \pm 1.2\end{array}$ & $\begin{array}{l}19.3 \pm 0.6 \\
19.1 \pm 0.6 \\
14.4 \pm 0.5 \\
10.3 \pm 0.5\end{array}$ & $\begin{array}{l}6.7 \pm 0.5 \\
6.5 \pm 0.5 \\
3.6 \pm 0.4 \\
0.3 \pm 0.1 \\
\end{array}$ & $\begin{array}{l}13.9 \pm 0.9 \\
14.6 \pm 0.8 \\
15.1 \pm 0.5 \\
15.4 \pm 0.4\end{array}$ & $\begin{array}{c}1.8 \pm 0.3 \\
3.0 \pm 0.2 \\
3.2 \pm 0.4 \\
2.2 \pm 0.5\end{array}$ & $\begin{array}{l}1.1 \pm 0.6 \\
1.1 \pm 0.6 \\
2.7 \pm 0.7 \\
0.9 \pm 0.5\end{array}$ & $\begin{array}{c}10.4 \pm 0.5 \\
8.2 \pm 0.4 \\
2.6 \pm 0.4 \\
7.6 \pm 0.4\end{array}$ & $\begin{array}{l}24.1 \pm 0.9 \\
25.8 \pm 0.9 \\
25.8 \pm 0.9 \\
25.6 \pm 1.1\end{array}$ \\
\hline
\end{tabular}


Table 4. Organic layer properties (elemental analysis, heating value, pH, total acid number and water content) after conventional pyrolysis of GSs and WTs, co-pyrolysis of GSs and WTs, catalytic pyrolysis of GSs and WTs and catalytic co-pyrolysis of GSs and WTs.

\begin{tabular}{|c|c|c|c|c|c|c|c|c|c|}
\hline & \multirow{2}{*}{$\begin{array}{c}\text { Experiment } \\
\text { GSs/WTs }(w t \%)\end{array}$} & \multicolumn{5}{|c|}{ Elemental analyses (wt\%) } & \multirow{2}{*}{$\begin{array}{c}\text { HHV } \\
(\mathbf{M J} / \mathbf{k g})\end{array}$} & \multirow{2}{*}{ pH } & \multirow{2}{*}{$\begin{array}{c}\text { TAN } \\
\left(\mathrm{mgKOH} / \mathrm{g}_{\text {bio-oil }}\right)\end{array}$} \\
\hline & & $\mathbf{C}$ & $\mathbf{H}$ & $\mathbf{N}$ & $\mathbf{S}$ & $\mathbf{O}^{1}$ & & & \\
\hline A. Conventional pyrolysis & $\begin{array}{l}100 / 0 \\
0 / 100\end{array}$ & $\begin{array}{l}73.9 \pm 0.1 \\
88.1 \pm 0.4\end{array}$ & $\begin{array}{c}9.2 \pm 0.1 \\
10.7 \pm 0.2\end{array}$ & $\begin{array}{l}2.5 \pm 0.2 \\
0.6 \pm 0.1\end{array}$ & $\begin{array}{l}0.0 \pm 0.0 \\
0.6 \pm 0.1\end{array}$ & $\begin{array}{c}14.3 \pm 0.4 \\
0.06 \pm 0.01\end{array}$ & $\begin{array}{l}36.8 \pm 0.5 \\
43.3 \pm 1.5\end{array}$ & $\begin{array}{l}6.4 \pm 0.0 \\
7.5 \pm 0.0\end{array}$ & $\begin{array}{c}33.4 \pm 1.9 \\
5.0 \pm 1.0\end{array}$ \\
\hline B. Co-pyrolysis of GSs and WTs & $\begin{array}{c}95 / 5 \\
90 / 10 \\
80 / 20 \\
60 / 40\end{array}$ & $\begin{array}{l}65.1 \pm 0.3 \\
70.8 \pm 0.1 \\
77.3 \pm 0.2 \\
80.5 \pm 0.4\end{array}$ & $\begin{array}{l}10.3 \pm 0.2 \\
10.0 \pm 0.3 \\
10.0 \pm 0.2 \\
11.0 \pm 0.3\end{array}$ & $\begin{array}{l}2.9 \pm 0.2 \\
2.3 \pm 0.1 \\
1.9 \pm 0.3 \\
1.3 \pm 0.3\end{array}$ & $\begin{array}{l}0.1 \pm 0.0 \\
0.2 \pm 0.0 \\
0.2 \pm 0.1 \\
0.4 \pm 0.1\end{array}$ & $\begin{array}{c}21.5 \pm 0.4 \\
16.5 \pm 0.2 \\
10.6 \pm 0.1 \\
6.6 \pm 0.1\end{array}$ & $\begin{array}{l}32.6 \pm 0.6 \\
34.8 \pm 0.6 \\
37.6 \pm 0.8 \\
40.4 \pm 1.1\end{array}$ & $\begin{array}{l}6.8 \pm 0.0 \\
6.5 \pm 0.0 \\
6.7 \pm 0.0 \\
6.5 \pm 0.0\end{array}$ & $\begin{array}{l}33.1 \pm 1.5 \\
32.3 \pm 1.4 \\
31.2 \pm 1.1 \\
14.2 \pm 1.8\end{array}$ \\
\hline $\begin{array}{l}\text { C. Theoretical co-pyrolysis of GSs and } \\
\mathrm{WSs}^{2}\end{array}$ & $\begin{array}{c}95 / 5 \\
90 / 10 \\
80 / 20 \\
60 / 40\end{array}$ & $\begin{array}{l}74.6 \pm 0.3 \\
75.3 \pm 0.3 \\
76.7 \pm 0.3 \\
79.6 \pm 0.2\end{array}$ & $\begin{array}{l}9.3 \pm 0.1 \\
9.4 \pm 0.1 \\
9.5 \pm 0.1 \\
9.8 \pm 0.1\end{array}$ & $\begin{array}{l}2.4 \pm 0.2 \\
2.3 \pm 0.1 \\
2.1 \pm 0.2 \\
1.7 \pm 0.1\end{array}$ & $\begin{array}{l}0.0 \pm 0.0 \\
0.1 \pm 0.0 \\
0.1 \pm 0.1 \\
0.2 \pm 0.1\end{array}$ & $\begin{array}{c}13.6 \pm 0.2 \\
12.9 \pm 0.1 \\
11.5 \pm 0.1 \\
8.6 \pm 0.1\end{array}$ & $\begin{array}{l}37.1 \pm 0.9 \\
37.5 \pm 0.8 \\
38.1 \pm 0.9 \\
39.4 \pm 1.0\end{array}$ & $\begin{array}{l}6.5 \pm 0.0 \\
6.5 \pm 0.0 \\
6.6 \pm 0.0 \\
6.8 \pm 0.0\end{array}$ & $\begin{array}{l}32.0 \pm 1.5 \\
30.6 \pm 1.2 \\
27.7 \pm 1.0 \\
22.1 \pm 1.0\end{array}$ \\
\hline $\begin{array}{l}\text { Catalytic reactions } \\
\text { D. Catalytic pyrolysis. Feedstock: } \mathrm{CaO} \\
1: 1\end{array}$ & $\begin{array}{l}100 / 0 \\
0 / 100\end{array}$ & $\begin{array}{l}69.6 \pm 0.1 \\
86.6 \pm 0.2\end{array}$ & $\begin{array}{l}10.5 \pm 0.2 \\
10.6 \pm 0.3\end{array}$ & $\begin{array}{l}3.1 \pm 0.2 \\
0.8 \pm 0.1\end{array}$ & $\begin{array}{l}0.0 \pm 0.0 \\
0.4 \pm 0.1\end{array}$ & $\begin{array}{c}16.6 \pm 0.1 \\
1.7 \pm 0.1\end{array}$ & $\begin{array}{l}34.9 \pm 0.6 \\
42.5 \pm 1.0\end{array}$ & $\begin{array}{l}9.8 \pm 0.0 \\
9.0 \pm 0.0\end{array}$ & $\begin{array}{l}<1 \\
<1\end{array}$ \\
\hline $\begin{array}{l}\text { E. Catalytic co-pyrolysis of GSs and WTs. } \\
\text { Feedstock: } \mathrm{CaO} 1: 1\end{array}$ & $\begin{array}{l}95 / 5 \\
90 / 10 \\
80 / 20 \\
60 / 40\end{array}$ & $\begin{array}{l}78.2 \pm 0.4 \\
81.4 \pm 0.3 \\
82.6 \pm 0.2 \\
84.3 \pm 0.4\end{array}$ & $\begin{array}{l}10.3 \pm 0.1 \\
10.8 \pm 0.1 \\
10.5 \pm 0.2 \\
10.1 \pm 0.1\end{array}$ & $\begin{array}{l}2.3 \pm 0.1 \\
2.1 \pm 0.2 \\
1.6 \pm 0.1 \\
1.0 \pm 0.1\end{array}$ & $\begin{aligned} & <0.1 \\
0.1 & \pm 0.1 \\
& <0.1 \\
0.2 & \pm 0.1\end{aligned}$ & $\begin{array}{l}9.2 \pm 0.2 \\
5.6 \pm 0.1 \\
5.3 \pm 0.1 \\
4.2 \pm 0.1\end{array}$ & $\begin{array}{l}39.4 \pm 0.7 \\
41.1 \pm 1.1 \\
41.2 \pm 1.1 \\
41.4 \pm 1.3\end{array}$ & $\begin{array}{c}9.3 \pm 0.0 \\
9.5 \pm 0.0 \\
9.1 \pm 0.0 \\
10.4 \pm 0.0\end{array}$ & $\begin{array}{l}<1 \\
<1 \\
<1 \\
<1\end{array}$ \\
\hline $\begin{array}{l}\text { F. Theoretical catalytic co-pyrolysis of } \\
\text { GSs and } \mathrm{WTs}^{3} \text {. Feedstock: } \mathrm{CaO} 1: 1\end{array}$ & $\begin{array}{l}95 / 5 \\
90 / 10 \\
80 / 20 \\
60 / 40\end{array}$ & $\begin{array}{l}70.5 \pm 0.3 \\
71.3 \pm 0.3 \\
73.0 \pm 0.2 \\
76.4 \pm 0.4\end{array}$ & $\begin{array}{l}10.5 \pm 0.4 \\
10.5 \pm 0.3 \\
10.5 \pm 0.2 \\
10.5 \pm 0.2\end{array}$ & $\begin{array}{l}3.0 \pm 0.3 \\
2.9 \pm 0.3 \\
2.6 \pm 0.1 \\
2.2 \pm 0.1\end{array}$ & $\begin{array}{l}0.0 \pm 0.0 \\
0.0 \pm 0.0 \\
0.1 \pm 0.1 \\
0.2 \pm 0.1\end{array}$ & $\begin{array}{l}15.9 \pm 0.2 \\
15.1 \pm 0.3 \\
13.6 \pm 0.2 \\
10.6 \pm 0.1\end{array}$ & $\begin{array}{l}41.2 \pm 1.1 \\
40.6 \pm 1.3 \\
41.2 \pm 1.2 \\
40.0 \pm 0.8\end{array}$ & $\begin{array}{l}9.8 \pm 0.0 \\
9.7 \pm 0.0 \\
9.6 \pm 0.0 \\
9.1 \pm 0.0\end{array}$ & $\begin{array}{l}<1 \\
<1 \\
<1 \\
<1\end{array}$ \\
\hline $\begin{array}{l}\text { G. Catalytic co-pyrolysis of GSs and } \\
\text { WTs. Variable Feedstock:CaO (in } \\
\text { brackets) }\end{array}$ & $\begin{array}{l}80 / 20(3: 1) \\
80 / 20(2: 1) \\
80 / 20(1: 1) \\
80 / 20(1: 2)\end{array}$ & $\begin{array}{l}82.6 \pm 0.3 \\
81.3 \pm 0.2 \\
82.8 \pm 0.3 \\
79.6 \pm 0.4\end{array}$ & $\begin{array}{l}10.5 \pm 0.3 \\
10.8 \pm 0.3 \\
10.8 \pm 0.2 \\
11.0 \pm 0.3\end{array}$ & $\begin{array}{l}1.6 \pm 0.1 \\
1.9 \pm 0.2 \\
1.6 \pm 0.1 \\
1.6 \pm 0.1\end{array}$ & $\begin{array}{l}0.0 \pm 0.0 \\
0.3 \pm 0.1 \\
0.2 \pm 0.1 \\
0.1 \pm 0.1\end{array}$ & $\begin{array}{l}5.3 \pm 0.2 \\
5.7 \pm 0.1 \\
4.6 \pm 0.1 \\
7.7 \pm 0.1\end{array}$ & $\begin{array}{l}41.2 \pm 1.0 \\
40.6 \pm 1.0 \\
41.2 \pm 1.0 \\
40.0 \pm 1.0\end{array}$ & $\begin{array}{l}9.1 \pm 0.0 \\
8.8 \pm 0.0 \\
9.2 \pm 0.0 \\
9.7 \pm 0.0\end{array}$ & $\begin{array}{l}<1 \\
<1 \\
<1 \\
<1\end{array}$ \\
\hline
\end{tabular}


Table 5. Ash composition of grape seeds

\begin{tabular}{lc}
\hline Ash composition of GSs & wt\% \\
\hline $\mathbf{A l}_{2} \mathbf{O}_{3}$ & $1.57 \pm 0.01$ \\
$\mathbf{C a O}$ & $27.05 \pm 0.05$ \\
$\mathbf{F e}_{2} \mathbf{O}_{3}$ & $1.04 \pm 0.02$ \\
$\mathrm{~K}_{2} \mathbf{O}$ & $24.20 \pm 0.02$ \\
$\mathbf{M g O}$ & $3.01 \pm 0.01$ \\
$\mathbf{M n O}_{2}$ & $0.20 \pm 0.01$ \\
$\mathrm{Na}_{2} \mathbf{O}$ & $0.27 \pm 0.01$ \\
$\mathbf{P}_{\mathbf{2}} \mathbf{O}_{5}$ & $11.16 \pm 0.03$ \\
$\mathrm{SiO}_{2}$ & $6.76 \pm 0.04$ \\
$\mathbf{T i O}_{2}$ & $0.05 \pm 0.01$ \\
\hline
\end{tabular}


Table 6. Organic layer chemical-composition determined by GC/MS (area \%).

\begin{tabular}{|c|c|c|c|c|c|c|c|c|c|c|c|c|}
\hline \multirow[b]{2}{*}{ Section } & \multirow[b]{2}{*}{$\begin{array}{c}\text { Experiment } \\
\text { GSs/WTs } \\
(w t \%)\end{array}$} & \multicolumn{11}{|c|}{ Chemical composition (area \%) } \\
\hline & & 总 & : & 光 & 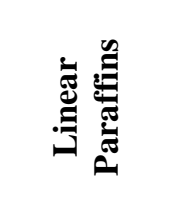 & $\frac{2}{0}$ & 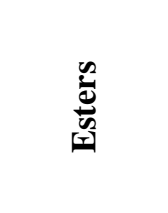 & $\frac{\mathscr{E}}{\tilde{E}}$ & 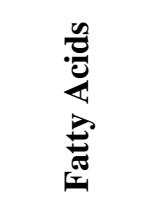 & $\frac{n}{0}$ & 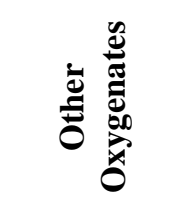 & 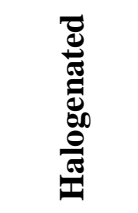 \\
\hline A. Conventional pyrolysis & $\begin{array}{l}100 / 0 \\
0 / 100\end{array}$ & $\begin{array}{c}7.5 \pm 0.8 \\
45.6 \pm 0.5\end{array}$ & $\begin{array}{c}0.0 \pm 0.0 \\
27.5 \pm 1.0\end{array}$ & $\begin{array}{l}4.6 \pm 0.5 \\
6.4 \pm 0.7\end{array}$ & $\begin{array}{l}10.8 \pm 0.6 \\
18.9 \pm 0.8\end{array}$ & $\begin{array}{l}2.3 \pm 0.5 \\
0.0 \pm 0.0\end{array}$ & $\begin{array}{c}11.8 \pm 0.7 \\
0.0 \pm 0.0\end{array}$ & $\begin{array}{l}1.9 \pm 0.5 \\
0.0 \pm 0.0\end{array}$ & $\begin{array}{l}4.3 \pm 0.8 \\
0.0 \pm 0.0\end{array}$ & $\begin{array}{c}46.2 \pm 1.0 \\
0.0 \pm 0.0\end{array}$ & $\begin{array}{l}5.8 \pm 0.8 \\
0.0 \pm 0.0\end{array}$ & $\begin{array}{l}4.7 \pm 0.7 \\
0.0 \pm 0.8\end{array}$ \\
\hline $\begin{array}{l}\text { B. Co-pyrolysis of GSs } \\
\text { and WTs }\end{array}$ & $\begin{array}{l}95 / 5 \\
90 / 10 \\
80 / 20 \\
60 / 40\end{array}$ & $\begin{array}{l}14.9 \pm 0.7 \\
13.5 \pm 0.8 \\
13.9 \pm 0.6 \\
14.3 \pm 1.0\end{array}$ & $\begin{array}{c}2.4 \pm 0.6 \\
7.2 \pm 0.8 \\
9.6 \pm 0.8 \\
17.3 \pm 0.8\end{array}$ & $\begin{array}{l}10.5 \pm 0.8 \\
12.2 \pm 0.8 \\
13.2 \pm 0.8 \\
14.7 \pm 0.8\end{array}$ & $\begin{array}{l}13.4 \pm 0.8 \\
12.8 \pm 0.7 \\
18.8 \pm 0.7 \\
30.3 \pm 1.0\end{array}$ & $\begin{array}{l}2.4 \pm 0.6 \\
2.8 \pm 0.8 \\
2.2 \pm 0.8 \\
2.3 \pm 0.5\end{array}$ & $\begin{array}{l}8.3 \pm 0.9 \\
7.9 \pm 0.6 \\
6.9 \pm 0.7 \\
5.3 \pm 0.8\end{array}$ & $\begin{array}{l}1.2 \pm 0.6 \\
1.6 \pm 0.5 \\
1.3 \pm 0.6 \\
1.1 \pm 0.6\end{array}$ & $\begin{array}{l}3.8 \pm 0.7 \\
3.5 \pm 0.6 \\
3.3 \pm 0.5 \\
3.0 \pm 0.9\end{array}$ & $\begin{array}{c}35.0 \pm 0.9 \\
29.8 \pm 0.8 \\
23.4 \pm 0.9 \\
6.2 \pm 0.5\end{array}$ & $\begin{array}{l}4.2 \pm 0.5 \\
4.6 \pm 0.8 \\
3.4 \pm 0.7 \\
2.4 \pm 0.7\end{array}$ & $\begin{array}{l}3.9 \pm 0.5 \\
4.0 \pm 0.5 \\
3.8 \pm 0.7 \\
3.1 \pm 0.8\end{array}$ \\
\hline $\begin{array}{l}\text { C. Theoretical co- } \\
\text { pyrolysis of GSs and } \\
\mathrm{WSs}^{1}\end{array}$ & $\begin{array}{l}95 / 5 \\
90 / 10 \\
80 / 20 \\
60 / 40\end{array}$ & $\begin{array}{l}9.4 \pm 0.9 \\
11.3 \pm 0.8 \\
15.1 \pm 0.6 \\
22.7 \pm 0.8\end{array}$ & $\begin{array}{c}1.4 \pm 0.5 \\
2.8 \pm 0.6 \\
5.5 \pm 0.6 \\
11.0 \pm 0.8\end{array}$ & $\begin{array}{l}4.7 \pm 0.5 \\
4.8 \pm 0.5 \\
5.0 \pm 0.8 \\
5.3 \pm 0.6\end{array}$ & $\begin{array}{l}11.2 \pm 0.6 \\
11.6 \pm 0.6 \\
12.4 \pm 0.8 \\
14.0 \pm 0.8\end{array}$ & $\begin{array}{l}2.2 \pm 0.8 \\
2.1 \pm 0.8 \\
1.8 \pm 0.7 \\
1.4 \pm 0.7\end{array}$ & $\begin{array}{c}11.2 \pm 0.6 \\
10.6 \pm 0.5 \\
9.4 \pm 0.7 \\
7.1 \pm 0.6\end{array}$ & $\begin{array}{l}1.8 \pm 0.8 \\
1.7 \pm 0.8 \\
1.5 \pm 0.7 \\
1.1 \pm 0.5\end{array}$ & $\begin{array}{l}4.1 \pm 0.9 \\
3.9 \pm 0.7 \\
3.4 \pm 0.6 \\
2.6 \pm 0.7\end{array}$ & $\begin{array}{l}43.9 \pm 1.0 \\
41.6 \pm 1.0 \\
37.0 \pm 0.9 \\
27.7 \pm 0.6\end{array}$ & $\begin{array}{l}5.5 \pm 0.6 \\
5.2 \pm 0.9 \\
4.6 \pm 0.9 \\
3.5 \pm 0.8\end{array}$ & $\begin{array}{l}4.5 \pm 0.9 \\
4.2 \pm 0.6 \\
3.8 \pm 0.7 \\
2.8 \pm 0.7\end{array}$ \\
\hline $\begin{array}{l}\text { Catalytic reactions } \\
\text { D. Catalytic pyrolysis. } \\
\text { Feedstock: } \mathrm{CaO} 1: 1\end{array}$ & $\begin{array}{l}100 / 0 \\
0 / 100\end{array}$ & $\begin{array}{l}14.1 \pm 0.5 \\
29.1 \pm 1.0\end{array}$ & $\begin{array}{c}0.0 \pm 0.0 \\
34.8 \pm 1.0\end{array}$ & $\begin{array}{l}17.9 \pm 0.8 \\
21.7 \pm 1.0\end{array}$ & $\begin{array}{l}11.1 \pm 0.7 \\
12.4 \pm 0.8\end{array}$ & $\begin{array}{l}6.0 \pm 0.8 \\
1.9 \pm 0.9\end{array}$ & $\begin{array}{l}5.2 \pm 0.9 \\
0.0 \pm 0.0\end{array}$ & $\begin{array}{c}12.3 \pm 1.0 \\
0.0 \pm 0.0\end{array}$ & $\begin{array}{l}3.9 \pm 0.8 \\
0.0 \pm 0.0\end{array}$ & $\begin{array}{l}9.6 \pm 0.5 \\
0.0 \pm 0.0\end{array}$ & $\begin{array}{c}13.9 \pm 0.7 \\
0.0 \pm 0.0\end{array}$ & $\begin{array}{l}4.8 \pm 0.9 \\
0.0 \pm 0.0\end{array}$ \\
\hline $\begin{array}{l}\text { E Catalytic co-pyrolysis } \\
\text { of GSs and WTs. } \\
\text { Feedstock: CaO } 1: 1\end{array}$ & $\begin{array}{l}95 / 5 \\
90 / 10 \\
80 / 20 \\
60 / 40\end{array}$ & $\begin{array}{l}9.3 \pm 0.8 \\
14.4 \pm 0.5 \\
15.6 \pm 0.6 \\
28.2 \pm 1.0\end{array}$ & $\begin{array}{c}2.7 \pm 0.6 \\
7.4 \pm 0.7 \\
8.5 \pm 0.8 \\
13.9 \pm 0.9\end{array}$ & $\begin{array}{c}8.2 \pm 0.6 \\
15.1 \pm 0.8 \\
16.7 \pm 0.8 \\
26.3 \pm 0.9\end{array}$ & $\begin{array}{c}13.0 \pm 0.8 \\
11.6 \pm 0.8 \\
11.1 \pm 0.8 \\
8.6 \pm 0.5\end{array}$ & $\begin{array}{l}4.0 \pm 0.8 \\
4.7 \pm 0.6 \\
4.7 \pm 0.6 \\
3.8 \pm 0.5\end{array}$ & $\begin{array}{l}7.6 \pm 0.6 \\
5.5 \pm 0.5 \\
5.6 \pm 0.8 \\
1.8 \pm 0.5\end{array}$ & $\begin{array}{c}17.9 \pm 1.0 \\
13.8 \pm 0.9 \\
13.6 \pm 0.8 \\
5.4 \pm 0.6\end{array}$ & $\begin{array}{l}6.5 \pm 0.9 \\
4.9 \pm 1.0 \\
5.0 \pm 0.5 \\
1.7 \pm 0.6\end{array}$ & $\begin{array}{c}10.5 \pm 0.6 \\
6.7 \pm 0.6 \\
4.6 \pm 0.5 \\
2.5 \pm 0.5\end{array}$ & $\begin{array}{c}13.7 \pm 0.8 \\
10.9 \pm 1.0 \\
10.1 \pm 0.9 \\
5.6 \pm 0.8\end{array}$ & $\begin{array}{l}6.4 \pm 0.7 \\
5.0 \pm 0.8 \\
4.6 \pm 0.7 \\
2.2 \pm 0.5\end{array}$ \\
\hline $\begin{array}{l}\text { F. Theoretical catalytic } \\
\text { co-pyrolysis of GSs and } \\
\text { WTs }{ }^{2} \text {. Feedstock: } \mathrm{CaO} \\
1: 1\end{array}$ & $\begin{array}{l}95 / 5 \\
90 / 10 \\
80 / 20 \\
60 / 40\end{array}$ & $\begin{array}{l}14.9 \pm 0.6 \\
15.6 \pm 0.7 \\
17.1 \pm 0.8 \\
20.1 \pm 1.0\end{array}$ & $\begin{array}{c}1.7 \pm 0.5 \\
3.5 \pm 0.5 \\
7.0 \pm 0.5 \\
13.9 \pm 0.8\end{array}$ & $\begin{array}{l}18.1 \pm 0.7 \\
18.3 \pm 0.7 \\
18.7 \pm 0.6 \\
19.4 \pm 0.8\end{array}$ & $\begin{array}{l}11.2 \pm 0.5 \\
11.2 \pm 0.9 \\
11.4 \pm 0.7 \\
11.6 \pm 0.8\end{array}$ & $\begin{array}{l}5.8 \pm 0.6 \\
5.6 \pm 0.5 \\
5.2 \pm 0.9 \\
4.4 \pm 0.5\end{array}$ & $\begin{array}{l}4.9 \pm 0.5 \\
4.7 \pm 0.5 \\
4.2 \pm 0.5 \\
3.1 \pm 0.5\end{array}$ & $\begin{array}{c}11.7 \pm 1.0 \\
11.1 \pm 1.0 \\
9.8 \pm 0.7 \\
7.4 \pm 0.7\end{array}$ & $\begin{array}{l}3.7 \pm 0.7 \\
3.5 \pm 0.8 \\
3.1 \pm 0.6 \\
2.3 \pm 0.9\end{array}$ & $\begin{array}{l}9.1 \pm 0.7 \\
8.6 \pm 0.8 \\
7.7 \pm 0.7 \\
5.8 \pm 0.5\end{array}$ & $\begin{array}{c}13.2 \pm 0.7 \\
12.5 \pm 0.7 \\
11.1 \pm 0.9 \\
8.3 \pm 0.6\end{array}$ & $\begin{array}{l}4.6 \pm 0.8 \\
4.3 \pm 0.8 \\
3.8 \pm 0.9 \\
2.9 \pm 0.6\end{array}$ \\
\hline $\begin{array}{l}\text { G. Catalytic co-pyrolysis } \\
\text { of GSs and WTs. Variable } \\
\text { Feedstock: } \mathrm{CaO} \text { (in } \\
\text { brackets) }\end{array}$ & $\begin{array}{l}80 / 20(3: 1) \\
80 / 20(2: 1) \\
80 / 20(1: 1) \\
80 / 20(1: 2) \\
\end{array}$ & $\begin{array}{l}9.8 \pm 0.6 \\
10.9 \pm 0.7 \\
15.7 \pm 0.9 \\
13.5 \pm 0.5\end{array}$ & $\begin{array}{l}10.4 \pm 0.9 \\
7.0 \pm 0.6 \\
8.5 \pm 0.7 \\
7.8 \pm 0.8 \\
\end{array}$ & $\begin{array}{c}8.2 \pm 0.6 \\
8.4 \pm 0.6 \\
15.9 \pm 0.8 \\
9.9 \pm 0.5 \\
\end{array}$ & $\begin{array}{l}14.9 \pm 0.5 \\
15.9 \pm 0.8 \\
11.1 \pm 0.8 \\
14.8 \pm 0.5 \\
\end{array}$ & $\begin{array}{l}4.0 \pm 0.5 \\
3.8 \pm 0.5 \\
4.8 \pm 0.7 \\
4.2 \pm 0.7 \\
\end{array}$ & $\begin{array}{l}7.2 \pm 0.8 \\
7.6 \pm 0.7 \\
5.5 \pm 0.6 \\
5.5 \pm 0.5 \\
\end{array}$ & $\begin{array}{l}11.7 \pm 1.0 \\
14.5 \pm 0.6 \\
13.2 \pm 0.7 \\
15.7 \pm 1.0 \\
\end{array}$ & $\begin{array}{l}4.7 \pm 0.5 \\
5.4 \pm 0.5 \\
4.9 \pm 0.5 \\
5.3 \pm 0.5\end{array}$ & $\begin{array}{l}13.7 \pm 0.9 \\
9.1 \pm 0.7 \\
4.6 \pm 0.6 \\
4.6 \pm 0.7 \\
\end{array}$ & $\begin{array}{l}9.9 \pm 0.5 \\
10.8 \pm 0.6 \\
10.9 \pm 0.9 \\
11.9 \pm 0.7\end{array}$ & $\begin{array}{l}4.4 \pm 0.5 \\
5.2 \pm 0.6 \\
4.2 \pm 0.9 \\
5.5 \pm 0.7 \\
\end{array}$ \\
\hline
\end{tabular}

